Review

\title{
Review of Graphene-Based Textile Strain Sensors, with Emphasis on Structure Activity Relationship
}

\author{
Rufang $\mathrm{Yu}^{1,2}$, Chengyan Zhu ${ }^{1,2}$, Junmin Wan ${ }^{2,3} \mathbb{D}$, Yongqiang $\mathrm{Li}^{1,2}$ and Xinghua Hong ${ }^{1,2, * \mathbb{C}}$ \\ 1 College of Textiles (International Silk Institute), Key Laboratory of Advanced Textile Materials and \\ Manufacturing Technology, Ministry of Education, Zhejiang Sci-Tech University, Hangzhou 310018, China; \\ 201930306004@mails.zstu.edu.cn (R.Y.); cyzhu@zstu.edu.cn (C.Z.); yqqli@163.com (Y.L.) \\ 2 Tongxiang Research Institute, Zhejiang Sci-Tech University, Tongxiang 314599, China; wwjm2001@126.com \\ 3 School of Materials Science and Engineering, Zhejiang Sci-Tech University, Hangzhou 310018, China \\ * Correspondence: xinghuahong@zstu.edu.cn; Tel.: +86-0571-86843262
}

Citation: Yu, R.; Zhu, C.; Wan, J.; Li, Y.; Hong, X. Review of GrapheneBased Textile Strain Sensors, with Emphasis on Structure Activity Relationship. Polymers 2021, 13, 151 https://doi.org/10.3390/ polym13010151

Received: 27 November 2020 Accepted: 29 December 2020 Published: 1 January 2021

Publisher's Note: MDPI stays neutral with regard to jurisdictional clai$\mathrm{ms}$ in published maps and institutional affiliations.

Copyright: (C) 2021 by the authors. Licensee MDPI, Basel, Switzerland. This article is an open access article distributed under the terms and conditions of the Creative Commons Attribution (CC BY) license (https:// creativecommons.org/licenses/by/ $4.0 /)$.

\begin{abstract}
Graphene-based textile strain sensors were reviewed in terms of their preparation methods, performance, and applications with particular attention on its forming method, the key properties (sensitivity, stability, sensing range and response time), and comparisons. Staple fiber strain sensors, staple and filament strain sensors, nonwoven fabric strain sensors, woven fabric strain sensors and knitted fabric strain sensors were summarized, respectively. (i) In general, graphene-based textile strain sensors can be obtained in two ways. One method is to prepare conductive textiles through spinning and weaving techniques, and the graphene worked as conductive filler. The other method is to deposit graphene-based materials on the surface of textiles, the graphene served as conductive coatings and colorants. (ii) The gauge factor (GF) value of sensor refers to its mechanical and electromechanical properties, which are the key evaluation indicators. We found the absolute value of GF of graphene-based textile strain sensor could be roughly divided into two trends according to its structural changes. Firstly, in the recoverable deformation stage, GF usually decreased with the increase of strain. Secondly, in the unrecoverable deformation stage, GF usually increased with the increase of strain. (iii) The main challenge of graphene-based textile strain sensors was that their application capacity received limited studies. Most of current studies only discussed washability, seldomly involving the impact of other environmental factors, including friction, $\mathrm{PH}$, etc. Based on these developments, this work was done to provide some merit to references and guidelines for the progress of future research on flexible and wearable electronics.
\end{abstract}

Keywords: textile strain sensors; graphene-based; staple fiber; staple and filament yarn; fabric

\section{Introduction}

The graphene-based textile strain sensor, pertaining to flexible and wearable strain sensors, is a smart material comprising the graphene, which is effectively able to sense the strain and stress. Sensing refers to the phenomenon in which the electrical resistance [1] and capacitance [2] of a material changes with the strain, etc. [3,4]. Flexible and wearable sensors have been greatly favored, mainly due to their wide applications including electronic skin [5-7], human-machine interfaces [8,9], human activities monitoring [10,11], intelligent robots [12], and human health detection $[13,14]$. Strain sensors possess the characteristics of high sensitivity, good flexibility, and good stretchability [15]. These capabilities are rendered by the embedding of devices and the use of conductive materials. Conventional strain sensors based on metal foils or semiconductors achieve good performance in terms of sensitivity. However, they are generally rigid, high weight, and have poor stretchability $(<5 \%)$, which means they are not truly flexible and wearable strain sensors $[8,16,17]$.

Various carbon materials [18], such as graphite [16,19,20], carbon black [21,22], carbon fiber [23], carbon nanotubes [24-26], and graphene [27-30], have been used to fabricate wearable strain sensors in recent years. Especially, graphene has been extensively studied 
for strain sensors due to its outstanding mechanical properties and conductivity, as shown in Figure 1. Graphene is a two-dimensional carbon nanomaterial, which is composed of a hexagonal honeycomb-like crystal lattice structure formed by $\mathrm{sp}^{2}$ hybridization carbon atoms [31-34]. Single-layer graphene was obtained by mechanical exfoliation (repeated peeling) of small mesas of highly-oriented pyrolytic graphite [35]. Structural and remarkable properties of graphene, including large surface area, prominent electrical properties, and excellent thermal and mechanical stability, make it a promising material for strain sensors [31,36-39]. Graphene oxide (GO) and reduced graphene oxide (RGO) are additional derivatives of graphene [40]. On the other hand, compared to other materials, textile materials are thin, flexible materials with a hierarchically porous structure, high surface area, and sufficient strength and tear resistance [41-43]. Therefore, for the achievement of wearable strain sensors with high sensitivity, good stability, and stretchability, the use of graphene to enhance functionality for textiles without the embedding of devices is remarkable.

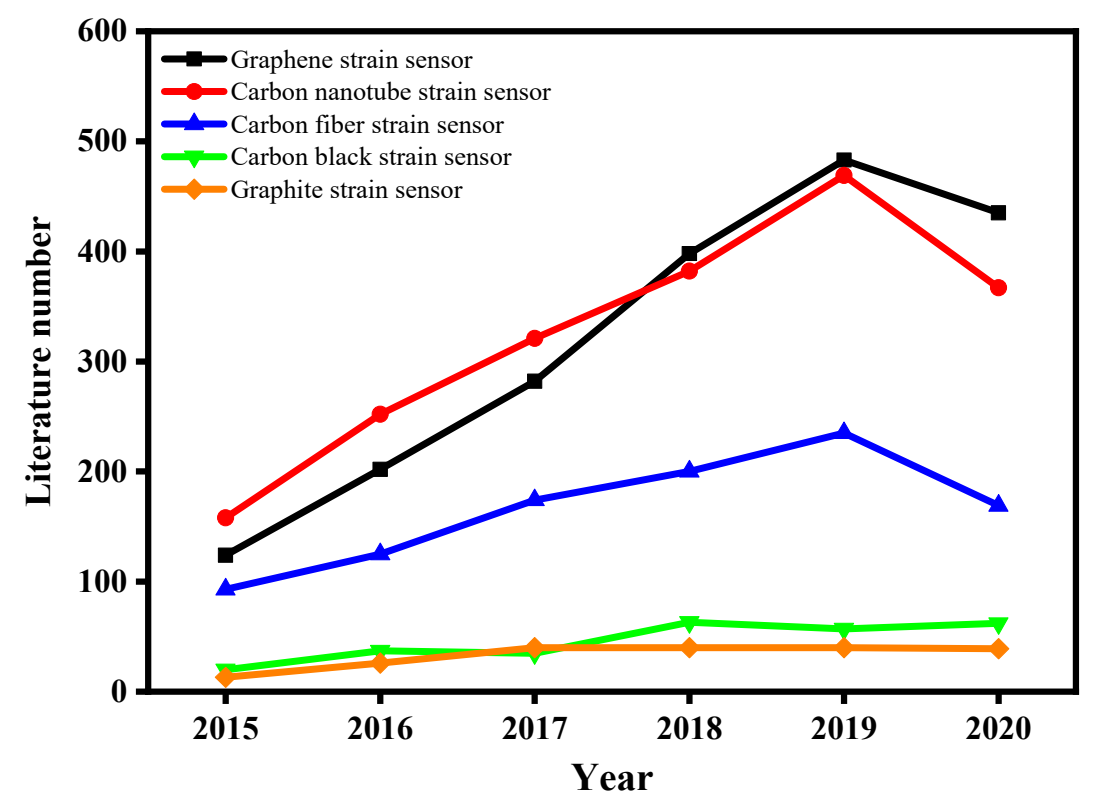

Figure 1. The development trend of carbon-based strain sensors in recent five years.

In this review, we aim to provide valuable guidelines for the preparation of flexible and wearable graphene-based textile strain sensors and to study the structural relationship between textile strain sensors and the absolute value of GF. According to different external morphological structures and production stages of textiles, the research progress of staple fiber strain sensors, staple and filament strain sensors and fabric strain sensors in recent years is introduced. The preparation method, performance and applications of graphenebased textile strain sensors are described. In general, there are two ways for preparing graphene-based textile strain sensors with prominent sensitivity and stability. One is to prepare conductive textiles via spinning and weaving techniques [44-53]. The other is depositing graphene-based materials on the surface of textiles [17,54-97].

When the graphene-based strain sensor is stretched by strain, its structural changes can be roughly divided into two processes. One is recoverable deformation when the textile sensor is subjected to a small strain; the other is irreversible deformation when the textile sensor is subjected to a large strain. Therefore, the GF absolute value of the textile strain sensor can be divided into two trends according to its structural changes, as shown in Figure 2. When a small strain is applied, its GF value decreases with the increase of strain, which may be ascribed to the decrease of contact point growth rate between fibers. When the strain exceeds the allowable range of fibers (refers to the natural extension of the fibers), the conductive networks attached to the single fiber surface are destroyed and 
rebuilt, leading to the sharp increase of GF. Cracks in the body of the material should be noted. Under huge strain, the sensing material will crack or even fracture, leading to the infinite increase of GF.

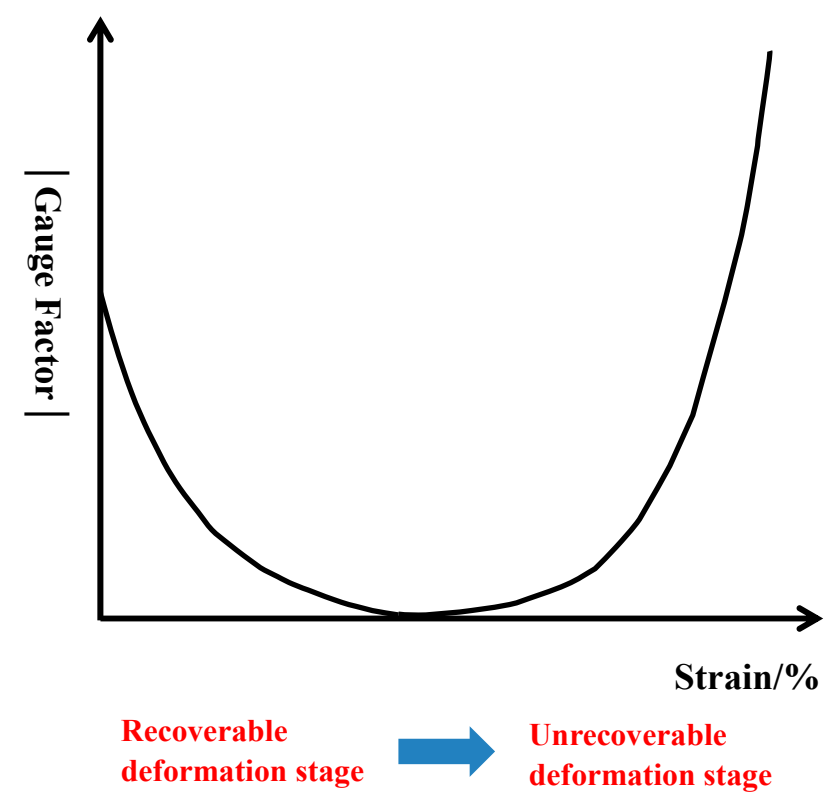

Figure 2. The general trend of GF absolute value of textile strain sensors according to their structure variation.

Graphene-based textile strain sensors are mainly used to sense a wide range of motions, from small (breathing, facial expressions, vocal sounds, coughing, and human pulse, etc.) to large (human limbs) $[45,46,50-52,57-59,61,62,64-66,68,70-72,76,78-80,83-88,91,94-97]$. Based on these developments, we summarize challenges and development prospects of graphene-based textile strain sensors, providing meaningful guidance and direction for future research.

\section{Performance Factors}

Textile strain sensors can be divided into resistive, capacitive, piezoelectric, triboelectric, and optical (Fiber Bragg Grating) [98]. The resistive type is widely used in textile strain sensors because it holds the superiorities of large measurement range, simple device structure, and high sensitivity [99], which is also the main focus of this review. The performance of textile strain sensors is generally evaluated from the aspects of GF, sensing range, long-term stability, and response time $[100,101]$.

Sensitivity is the most important property of strain sensor, which is usually expressed by GF. GF is the relative resistance that changes with strain, which is expressed in Equation (1).

$$
\mathrm{GF}=\frac{\Delta R / R_{0}}{\varepsilon}
$$

In the equation, $R_{0}$ is the resistance of the sensor at the initial (unstrained) state, $\Delta R$ is the difference between the resistance $(R)$ at the stretched state and the resistance $\left(R_{0}\right)$ at the initial state, and $\varepsilon$ indicates the mechanical strain. Therefore, the strain range of GF values should be indicated. The larger the GF, the more sensitive the strain sensor is. The resistance changes reversibly and irreversibly under the strain. The reversible change of resistance is related to strain sensing, so the strain used in the test should not be too large. Similarly, linearity is true within a certain range of deformation. In addition, the response time of sensors to the strain can also reflect the sensitivity.

The sensing range refers to the range of strain that can be detected by sensors, and it is one of the reference factors for sensors application. Stability refers to the performance of the 
textile strain sensor that can recover to the initial state after being stretched for many times. In the process of practical application, the textile strain sensor is bound to be stretched and worn for many times, so the stability is very important for it. Furthermore, textile strain sensors for flexible and wearable electronics should possess excellent comfort, light weight, and durability.

\section{Preparation Methods and Performance Evaluation}

From fibers to fabrics, textiles possess many unique properties including durability, conformability, deformability, breathability, and washability [68]. Therefore, the textile is regarded as an ideal material for developing strain sensors with high sensitivity and stability, although the conductivity and electrochemical properties of textile materials are poor [42]. According to production stages and the morphological structure of textiles, the preparation methods and performance of staple fiber strain sensors, staple and filament yarn strain sensors, and fabric strain sensors are discussed.

\subsection{Graphene-Based Fiber and Yarn Strain Sensors}

Fiber and yarn are widely used as sensor accessories applied to strain sensors, owing to their flexibility, adjustability, wide applicability, and low cost. They can be designed as strain sensors combining with graphene-based materials. The research of graphene-based fiber and yarn strain sensors is introduced in detail in the following sections.

\subsubsection{Staple Fiber Strain Sensors}

Fibers are the most primitive state of textiles, which can be divided into natural fibers and chemical fibers according to the materials. There are a great variety of fibers with different characteristics. For example, silk fibers have high tensile strength, toughness, and excellent elasticity [102]. Cotton fibers possess numerous advantages, such as easy processing, relatively low cost, and good strength and chemical resistance [103]. Polyester fibers have high strength, good chemical stability, and suitable extension and rebound performance [104]. These outstanding properties make fibers an ideal material for preparing strain sensors. Nevertheless, most fibers, such as natural fibers (cotton, silk, wool, etc.), polymer fibers (polyurethane, polyester, polyamide, etc.) and so on, are typically not capable of electrical conductivity. Even among conductive fibers (such as graphene fibers and RGO fibers), most of them have poor strength, low elongation and elasticity, and are fragile under external force $[105,106]$. These shortcomings hinder their promising applications in strain sensors. Therefore, some techniques are used to eliminate these shortcomings, with the purpose of fabricating fiber strain sensors. For instance, Yin et al. [64] fabricate a wearable sensor through dipping cellulose acetate fiber (CAF) bundles into the as-prepared RGO solution. Huang et al. [57] manufacture porous graphene fibers (PGFs) decorated with nanoballs via a facile phase separation method (Figure 3a). Wang et al. [44] fabricate a strain sensor based on conductive poly(styrene-butadienestyrene)/few layer graphene (SBS/FLG) composite fiber through wet-spinning method. Li et al. [45] adopt a simple wet-spinning to prepare a composite fiber-based strain sensor (Figure 3b).

Various methods for the fabrication of fiber strain sensors, including chemical vapor deposition (CVD) (Figure 3c) [55,56], phase separation [57], dip-coating (Figure 3d) [64-66,69], and spinning [44-50] have been extensively investigated. Preparation methods have important effects on properties of strain sensors, especially in sensitivity. The strain sensor prepared by dipping method possesses a wide sensing range (0.05-75\%), but it owns a low sensitivity with a GF of -8.9 in lower than $5 \%$ strain [64]. The PGFs fabricated by a phase separation method show relatively high gauge factors (51 in $0-5 \%$ and 87 in 5-8\%) [57]. Jiang et al. [46] employ wet-spinning to prepare a flexible sensor with an ultrahigh gauge factor (1668). Li et al. [50] manufacture a RGO nanosheet-wrapped thermoplastic polyurethane (TPU) fibrous mat through electrospinning, which exhibits great sensitivity (GF of $\sim 50$ at a strain of $50 \%$ ). 
(a)

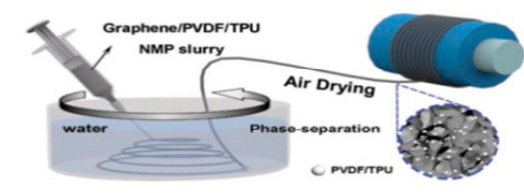

Phase separation (b)

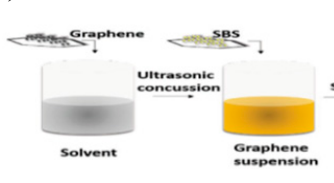

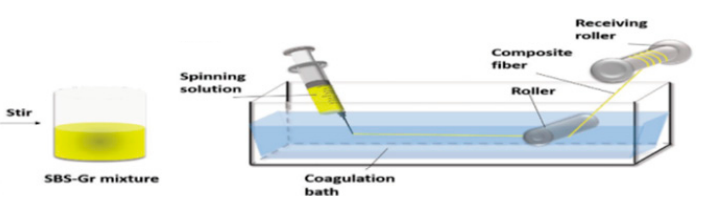

Wet-spinning (c)

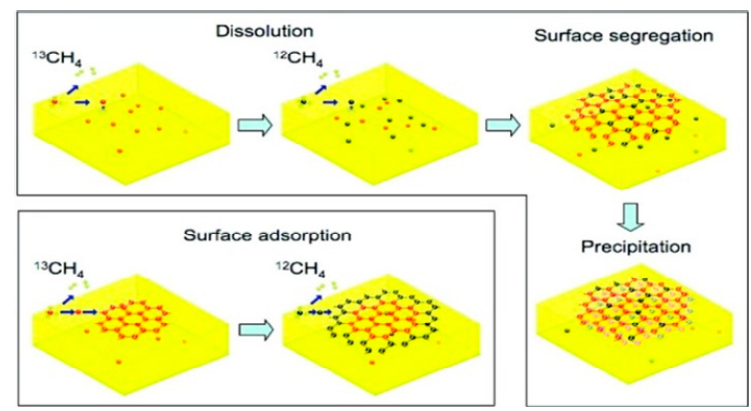

CVD

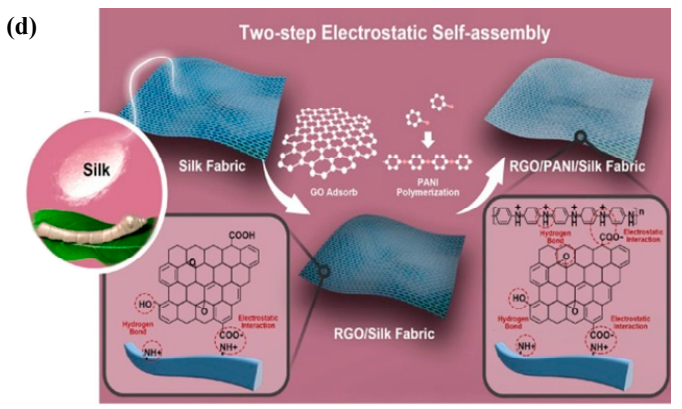

Dip-coating (e)

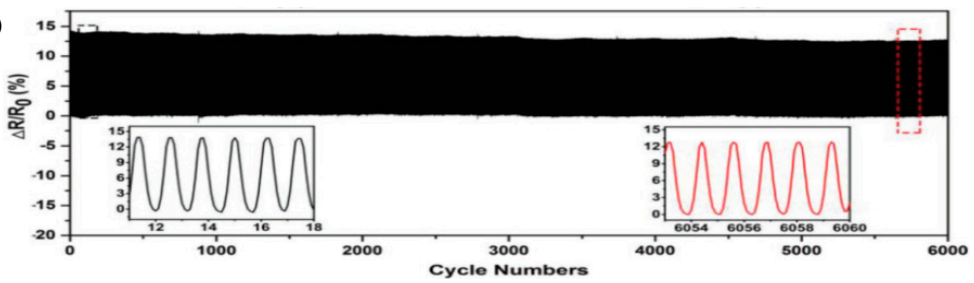

(f)

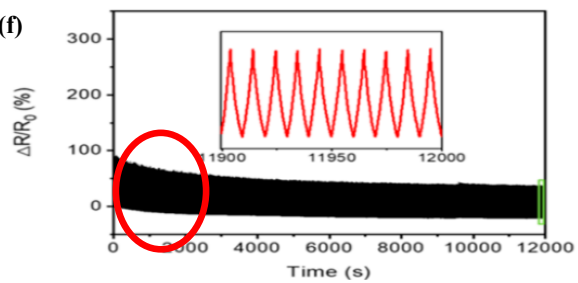

Figure 3. Fabrication and performance of graphene-based textile strain sensors. (a) Schematic illustration showing the fabrication of PGFs via a phase separation method. "Adapted with permission from reference [57]. Copyright [2019], Advanced Functional Materials". (b) Schematic illustration for preparing poly (styrene-butadiene-styrene)/graphene composite fibers through a wet-spinning method. "Adapted with permission from reference [45]. Copyright [2020], Macromolecular Materials and Engineering". (c) Durability of the PGFs strain sensors after 6000 cycles at a 1\% strain stretch and release. "Adapted with permission from reference [57]. Copyright [2019], Advanced Functional Materials". (d) Stability of the rGOFF strain sensor under a repeated applied strain of 20.0\%. "Adapted with permission from reference [46]. Copyright [2019], ACS Applied Materials \& Interfaces". (e) Schematic diagram of CVD method. "Adapted with permission from reference [107]. Copyright [2009], Nano Letters". (f) Schematic diagram of dip-coating method. "Adapted with permission from reference [108]. Copyright [2020], ACS Applied Materials \& Interfaces".

The properties of various graphene-based staple fiber strain sensors of prior works are summarized in Table 1, and the attributes listed include type, main materials, fabrication method, GF, sensing range, stability, response time, and application. The following points are worth noting:

(1) Relationship between GF absolute value and structure.

With the increase of strain range, GF increases [44,45,57], which is due to the destruction and reconstruction of the conductive networks on the fiber surface. When the fiber is stretched by a small external force, a small deformation occurs, resulting in disconnection of the conductive networks contacts, and GF slowly increases. When a higher strain is applied, the conductive networks of the fiber break and irreversible damage occurs, leading to a sharp change in its resistance and a rapid rise in GF. 
Table 1. Properties of various graphene-based staple fiber strain sensors.

\begin{tabular}{|c|c|c|c|c|c|c|c|c|}
\hline Main Materials & Substrate & $\begin{array}{l}\text { Fabrication } \\
\text { Method }\end{array}$ & GF & $\begin{array}{c}\text { Sensing } \\
\text { Range (\%) }\end{array}$ & $\begin{array}{l}\text { Stability } \\
\text { (Cycle) }\end{array}$ & $\begin{array}{c}\text { Response Time } \\
\text { (ms) }\end{array}$ & Application & References \\
\hline Graphene & Graphene fiber & CVD & $\begin{array}{c}34.3-48.9 \\
\text { (8\% strain) }\end{array}$ & - & - & - & - & [55] \\
\hline RGO & $\begin{array}{l}\text { Cellulose acetate } \\
\text { fiber bundles }\end{array}$ & Dipping & $\begin{array}{c}-8.9 \\
(<5 \% \text { strain })\end{array}$ & $0.05-75$ & $\begin{array}{c}580 \\
(0.3 \% \text { strain })\end{array}$ & - & $\begin{array}{l}\text { Monitor full-range } \\
\text { human motions }\end{array}$ & {$[64]$} \\
\hline $\begin{array}{c}\text { Graphene/ } \\
\text { polyvinylidene } \\
\text { fluo- } \\
\text { ride/polyurethane }\end{array}$ & graphene fiber & Phase-separation & $\begin{array}{l}51(0-5 \% \text { strain }) \\
87(5-8 \% \text { strain })\end{array}$ & - & $\begin{array}{c}6000 \\
(1 \% \text { strain })\end{array}$ & $<100$ & $\begin{array}{l}\text { Monitor a pulse } \\
\text { wave, eyeball } \\
\text { movement and } \\
\text { joint motion }\end{array}$ & [57] \\
\hline SBS/FLG & $\begin{array}{c}\text { SBS/FLG } \\
\text { composite fibers }\end{array}$ & Wet-spinning & $\begin{array}{c}160 \text { (50\% strain) } \\
2546 \text { (100\% strain) }\end{array}$ & $>110$ & - & - & - & [44] \\
\hline SBS/graphene & $\begin{array}{l}\text { SBS/graphene } \\
\text { composite fibers }\end{array}$ & Wet-spinning & $\begin{array}{c}56(0-40 \% \text { strain }) \\
1592 \\
(40-73 \% \text { strain }) \\
10,084 \\
\text { (73-100\% strain) }\end{array}$ & Up to 100 & $\begin{array}{c}2100 \\
(20 \% \text { strain })\end{array}$ & - & $\begin{array}{l}\text { Detect human } \\
\text { upper limb } \\
\text { movements in } \\
\text { different joints }\end{array}$ & [45] \\
\hline $\mathrm{RGO} / \mathrm{TPU}$ & RGO/TPU fibers & Electrospinning & $\begin{array}{c}\sim 50 \\
(50 \% \text { strain })\end{array}$ & $0-150$ & $\begin{array}{c}500 \\
(150 \% \text { strain })\end{array}$ & $<160$ & $\begin{array}{l}\text { Monitor full-range } \\
\text { human motions }\end{array}$ & {$[50]$} \\
\hline
\end{tabular}




\section{(2) Stability.}

Stability of the graphene-based fiber sensor depends on the number of stretching cycles and the strain. Suppose stability can be defined as the number of stretching cycles multiplied by strain. The larger the value is, the better stability of the strain sensor will be. For instance, the PGFs show great durability (over 6000 cycles at $1 \%$ strain) (Figure 3e) [57]. Jiang et al. [46] prepare a flexible sensor with a great durability and stability (within 1200 cycles under a strain of $20 \%$ ), as illustrated in Figure 3f. In addition, it can be found that the stability of the fiber sensor fluctuates within a certain range during the high strain stretching cycles, which may be caused by the recombination of the conductive networks. This does not affect the stability of fiber strain sensors.

\subsubsection{Staple and Filament Yarn Strain Sensors}

Yarns are a kind of textile with a certain fineness processed from various fibers. They have a higher strain range than fibers thanks to inter-fiber slip, which comes from twisting without chemical bonding. Furthermore, staple and filament yarns possess soft, skin-friendly, tensile-stable characters and good biocompatibility [109]. These excellent properties make them attractive for the fabrication of strain sensors comprising graphene, etc. Wang et al. [54] fabricate poly(vinyl alcohol) coating graphene (G@PVA) core-sheath fibers filament by the use of a simple polymer coating method and chemical vapor deposition (CVD)-grown graphene nanofibers. However, the sensing range is only $16 \%$, and a low sensitivity is observed, with a GF of $~ 5.02$ under 1-6.3\% strain [54]. Graphene and polymers can be employed as raw materials to fabricate filament yarn strain sensors via spinning technologies [51-53]. Yan et al. [51] fabricate composite nanofiber yarn strain sensors by electrospinning. The average GF of the sensor is $>1700$ under an applied strain of $2 \%$.

Nevertheless, the method of combining graphene-based materials with yarns through dip-coating [58,59,65-68,70], layer-by-layer (LbL) assembly [60-63] is more widely used. Hamid Souri et al. [58] coat natural fiber yarns with graphene nanoplatelets (GNPs) and carbon black (CB) to obtain conductive yarns. However, it holds a low sensitivity with a GF of 5.62 under $4 \%$ strain. Cheng et al. [65] dip-coat a yarn with GO and reduced by hydroiodic acid to obtain a RGO coated filament yarn. Niu et al. [68] adopt a dip-coating method to obtain a strain sensor based on polydopamine/reduced graphene oxide/polyurethane yarn (PDA/rGO/PUY). Li et al. [60] coat graphene onto a polyurethane (PU) core via a layer-by-layer assembly method. The strain sensor possesses a high GF of 86.86 and excellent thermal stability. Besides, to further increase the sensitivity, Li et al. [61] use graphene-microsheets (GMs)/PU strain sensing yarns to prepare a flexible strain sensor, which is endowed with high sensitivity (a GF of 490.2 under an applied strain of 50\%). More importantly, the strain sensing yarns can be directly woven into fabric to make a wearable and flexible strain sensing fabric. Li et al. [63] also fabricate a yarn strain sensor based on graphene nanosheets/thin gold film/graphene nanosheets/polyurethane (GNSs/ Au/GNSs/PU). It possesses a high GF ( $\sim 662$ within 50\% strain), remarkable stability, and waterproof property. In short, the properties of the strain sensors prepared by different methods are disparate.

The performance of the graphene-based staple and filament yarn strain sensor is not only related to the preparation method, but also closely related to the type of yarns. Jung Jin Park et al. [62] adopt LBL assembly technique to manufacture three types of strain sensors, made from different yarns (rubber (RY), nylon covered rubber (NCRY), and wool yarn (WY)). These yarn sensors show different sensitivities with GFs ( 1800 (RY), 1.4 (NCRY), and $-0.1(\mathrm{WY})$ ).

The performance of various graphene-based staple and filament yarn strain sensors are summarized in Table 2. It can be found that the GF absolute value of staple and filament yarn strain sensors present different variation trends with the increase of strain $[59,65,66,68,70]$. In the process of stretching, yarn deformation can be divided into two processes. One is recoverable micro-deformation. The contact point between yarns 
decreases with the increase of strain, leading to the decrease of GF $[65,66,70]$. The other is irreversible deformation that occurs when the strain exceeds the allowable range of the yarn. The conductive networks on the yarn surface are destroyed and restructured, which leads to the increase of GF $[59,68]$.

To sum up, two methods are adopted to obtain flexible fiber and yarn strain sensors. One is to prepare conductive fiber and yarn by various spinning technologies, such as liquid crystal spinning [49], wet spinning [44-48], or electrospinning [50-53]. The other is to deposit graphene-based materials on the surface of fibers/yarns by CVD [54-56], vaporphase polymerization [57], layer-by-layer (LbL) assembly [60-63], dip-coating [58,59,64-70], among others. The prepared graphene-based fiber and yarn strain sensors are endowed with good sensitivity, stability, and sensing range, but most of them act as the accessories of clothes or the independent devices, and still cannot provide satisfactory comfort [70]. Most of the graphene-based fiber and yarn strain sensors need flexible substrates such as PDMS [49,54,55,57,62,64,65], Ecoflex [58,59], or TPU [51] to protect their structure because sensing fibers and yarns are easily damaged. Designing graphene-based fibers and yarns strain sensors that are endowed with prominent sensitivity and a wide sensing range, yet satisfactory comfort remains a big challenge.

\subsection{Graphene-Based Fabric Strain Sensors}

Fabrics refer to sheet objects made of textile yarns, which have good wearing comfort and softness. However, they still have several drawbacks, including unsatisfactory mechanical properties of the stretchable substrate and poor electrical conductivity [110]. Various methods are employed to combine fabrics with graphene-based materials, with the aim of converting them into highly conductive materials. According to the different processing methods of fabrics, the preparation and properties of nonwoven, woven, and knitting fabric strain sensors are discussed in detailed.

\subsubsection{Nonwoven Fabric Strain Sensors}

Nonwoven fabrics are kinds of fabrics that do not need spinning and weaving. They only need to arrange short textile fibers or filaments in a directional or random way [111] to form a fiber net structure, and then they are reinforced by mechanical, thermal bonding, or chemical methods. Nonwoven fabrics break through the traditional textile principle and have the advantages of low cost, fast production speed, wide applications and recyclability. Therefore, strain sensors prepared by nonwoven fabrics (NWF) as sensing substrate attract considerable attention. Qu et al. [85] employ a scalable screen-printing process for creating GO patterns onto viscose nonwoven fabrics. The sensing fabric is highly sensitive to compression, good wash fastness. A strain sensor based on RGO/polyester (PET) fabrics are manufactured via suction filtration and reduction [86]. It holds durability (150 bending cycles under $10 \%$ strain) and electrothermal property. M. Simard-Normandin et al. [73] adopt a spray coating technology to fabricate a graphene-based nonwoven fabric, which exhibits good performance in terms of sensitivity (GF of 9.43 and 9 under a strain of $20 \%$ and $1 \%$, respectively), durability, and stability. Du et al. [71] prepare a graphene-NWF (GNWF) strain sensor by a dip-and-reduce method. The sensor possesses a negative GF of -7.1 , great stretchability, and stability (up to 10,000 cycles at $1 \%$ strain). Furthermore, it can be directly integrated into clothes. The RGO/carbon nanotubes (CNTs)/NWF sensors [72] with great stability, a high GF (32.65 at 1.0\% strain), and high machine washability (the resistance of RGO/CNTs/NWF textile changes from $\sim 31$ to $\sim 36 \mathrm{k} \Omega$ after 6 washing cycles) are prepared by the same method. Liu et al. [87] adopt a dip-coating method to fabricate a strain sensor, which shows excellent performance, including an ultra-sensitivity (180 at 15\% strain), good stability, and excellent self-cleaning, anti-corrosion ability, and waterproofness.

The performance of various graphene-based nonwoven strain sensors is shown in Table 3 , and the following points can be found. 
Table 2. Properties of various graphene-based staple and filament yarn strain sensors.

\begin{tabular}{|c|c|c|c|c|c|c|c|c|c|}
\hline Main Materials & Substrate & $\begin{array}{c}\text { Fabrication } \\
\text { Method }\end{array}$ & GF & $\begin{array}{l}\text { Sensing Range } \\
(\%)\end{array}$ & $\begin{array}{l}\text { Stability } \\
\text { (Cycle) }\end{array}$ & $\begin{array}{l}\text { Response Time } \\
\text { (ms) }\end{array}$ & Application & $\begin{array}{c}\text { Other } \\
\text { Advantages }\end{array}$ & References \\
\hline Graphene/PVA & Graphene fiber & CVD/coating & $\begin{array}{c}\sim 5.02 \\
(1-6.3 \% \text { strain }) \\
\end{array}$ & Up to 16 & $\begin{array}{c}200 \\
\text { (6\% strain) }\end{array}$ & - & - & - & [54] \\
\hline Carbon/graphene & $\begin{array}{l}\text { Carbon/graphene } \\
\text { composites } \\
\text { nanofiber yarn }\end{array}$ & Electrospinning & $\begin{array}{c}>1700 \\
(2 \% \text { strain })\end{array}$ & - & $\begin{array}{c}300 \\
(2 \% \text { strain })\end{array}$ & - & $\begin{array}{l}\text { Detect sound } \\
\text { waves and tiny } \\
\text { muscle } \\
\text { movements }\end{array}$ & - & [51] \\
\hline GNPs/CB & $\begin{array}{l}\text { Natural fiber } \\
\text { yarn including } \\
\text { flax and } \\
\text { flax-bleached }\end{array}$ & Dip-coating & $\begin{array}{c}5.62 \\
\text { (4\% strain) }\end{array}$ & Up to 60 & $\begin{array}{c}>1000 \\
(8 \% \text { strain })\end{array}$ & $<209$ & $\begin{array}{c}\text { Monitor various } \\
\text { human } \\
\text { movements }\end{array}$ & - & [58] \\
\hline $\begin{array}{l}\text { GNPs/CB/ } \\
\text { conductive ink }\end{array}$ & Wool yarn & Dip-coating & $\begin{array}{c}5(0-127 \% \\
\text { strain) } 7.75 \\
(127-200 \% \text { strain })\end{array}$ & Up to 200 & $\begin{array}{c}1100 \\
\text { (75\% strain) }\end{array}$ & $\sim 172$ & $\begin{array}{l}\text { Detect various } \\
\text { human } \\
\text { movements }\end{array}$ & - & [59] \\
\hline RGO & $\begin{array}{c}\text { A } \\
\text { double-covered } \\
\text { yarn (PU core } \\
\text { fiber and } \\
\text { polyester fibers) }\end{array}$ & Dip-coating & $\begin{array}{c}10(<1 \% \text { strain }) \\
3.7(<50 \% \text { strain })\end{array}$ & Up to 100 & $\begin{array}{c}10,000 \\
(30 \% \text { and } 50 \% \\
\text { strain) }\end{array}$ & $<100$ & $\begin{array}{l}\text { Monitor a wide } \\
\text { variety of } \\
\text { human activities } \\
\text { and complex } \\
\text { robot } \\
\text { movements }\end{array}$ & - & {$[65]$} \\
\hline RGO & $\begin{array}{c}\text { A } \\
\text { double-covered } \\
\text { yarn }(\sim 650 \mu \mathrm{m} \text { in } \\
\text { diameter })\end{array}$ & Dip-coating & $\begin{array}{c}8.8(5 \% \text { strain }) \\
5.4(10 \% \text { strain }) \\
1.6(100 \% \text { strain })\end{array}$ & 0-105 & $\begin{array}{c}2000 \\
\text { (50\% strain) }\end{array}$ & - & $\begin{array}{l}\text { Monitor } \\
\text { full-scale human } \\
\text { motions }\end{array}$ & - & [66] \\
\hline RGO & PU yarn & Dip-coating & $\begin{array}{c}50(<50 \% \text { strain }) \\
\sim 132 \\
(90 \% \text { strain })\end{array}$ & $0-90$ & $\begin{array}{c}30,000 \\
(50 \% \text { strain })\end{array}$ & - & $\begin{array}{l}\text { Monitor various } \\
\text { human motions }\end{array}$ & $\begin{array}{l}\text { Can be } \\
\text { integrated into } \\
\text { fabric structure }\end{array}$ & [68] \\
\hline
\end{tabular}


Table 2. Cont.

\begin{tabular}{|c|c|c|c|c|c|c|c|c|c|}
\hline Main Materials & Substrate & $\begin{array}{l}\text { Fabrication } \\
\text { Method }\end{array}$ & GF & $\begin{array}{c}\text { Sensing Range } \\
(\%)\end{array}$ & $\begin{array}{l}\text { Stability } \\
\text { (Cycle) }\end{array}$ & $\begin{array}{c}\text { Response Time } \\
(\mathrm{ms})\end{array}$ & Application & $\begin{array}{c}\text { Other } \\
\text { Advantages }\end{array}$ & References \\
\hline Graphene & Nylon filament & Dip-coating & $\begin{array}{c}0.08 \\
(<12 \% \text { strain }) \\
0.07 \\
(12-33 \% \text { strain }) \\
0.22 \\
(33-45.69 \% \text { strain })\end{array}$ & Up to 45.69 & $\begin{array}{c}2800 \\
(40 \% \text { strain })\end{array}$ & - & $\begin{array}{l}\text { Monitor human } \\
\text { breathing and } \\
\text { joint movement }\end{array}$ & - & {$[70]$} \\
\hline Graphene/PVA & PU yarn & $\mathrm{LbL}$ & $\sim 87$ & - & $\begin{array}{c}100 \\
\text { (50\% strain) }\end{array}$ & - & - & $\begin{array}{l}\text { Thermal } \\
\text { stability (within } \\
\text { the range of } \\
25-310^{\circ} \mathrm{C} \text { ) }\end{array}$ & {$[60]$} \\
\hline $\begin{array}{c}\text { GMs/ } \\
\text { Ag- } \\
\text { nanoparticles }\end{array}$ & PU yarn & $\mathrm{LbL}$ & $\begin{array}{c}\sim 500 \\
(50 \% \text { strain })\end{array}$ & $0-50$ & $\begin{array}{c}2000 \\
\text { (50\% strain) }\end{array}$ & - & $\begin{array}{c}\text { Monitor of } \\
\text { human motions }\end{array}$ & $\begin{array}{c}\text { Can be directly } \\
\text { woven into } \\
\text { textiles }\end{array}$ & [61] \\
\hline $\begin{array}{l}\text { GNSs/Au/ } \\
\text { GNSs/PU }\end{array}$ & PU yarn & $\mathrm{LbL}$ & $\begin{array}{c}\sim 662 \\
(0-50 \% \text { strain })\end{array}$ & $0-75$ & $\begin{array}{c}10,000 \\
(50 \% \text { strain) }\end{array}$ & - & $\begin{array}{l}\text { Monitoring } \\
\text { various human } \\
\text { motions and } \\
\text { control a } \\
\text { hand robot }\end{array}$ & $\begin{array}{l}\text { Waterproof } \\
\text { property }\end{array}$ & [63] \\
\hline GNP & RY & $\mathrm{LbL}$ & $\sim 1800$ & Up to 100 & 10 (80\% strain) & - & $\begin{array}{c}\text { Detect } \\
\text { small-scale } \\
\text { motions }\end{array}$ & - & [62] \\
\hline GNP & NCRY & $\mathrm{LbL}$ & 1.4 & Up to 150 & 10 (100\% strain) & - & $\begin{array}{c}\text { Detect } \\
\text { large-scale } \\
\text { motion }\end{array}$ & - & [62] \\
\hline GNP & WY & $\mathrm{LbL}$ & -0.1 & Up to 50 & 10 (40\% strain) & - & - & - & [62] \\
\hline
\end{tabular}


Table 3. Performance of various graphene-based nonwoven strain sensors.

\begin{tabular}{|c|c|c|c|c|c|c|c|c|c|}
\hline Main Materials & Substrate & $\begin{array}{c}\text { Fabrication } \\
\text { Method }\end{array}$ & GF & $\begin{array}{c}\text { Sensing Range } \\
(\%)\end{array}$ & $\begin{array}{l}\text { Stability } \\
\text { (Cycle) }\end{array}$ & $\begin{array}{l}\text { Response Time } \\
\text { (ms) }\end{array}$ & Application & $\begin{array}{c}\text { Other } \\
\text { Advantages }\end{array}$ & References \\
\hline GO & $\begin{array}{l}\text { Viscose } \\
\text { nonwoven } \\
\text { fabrics }\end{array}$ & Screen-printing & - & - & - & - & $\begin{array}{l}\text { Detect the } \\
\text { bending } \\
\text { movements of } \\
\text { wrist joint }\end{array}$ & $\begin{array}{c}\text { Washing } \\
\text { fastness (sheet } \\
\text { resistance } \\
\text { changes from } \\
\sim 1.6 \text { to } \sim 7.1 \\
\mathrm{k} \Omega / \text { sq after } 5 \\
\text { washing cycles) }\end{array}$ & [85] \\
\hline RGO & $\begin{array}{l}\text { PET nonwoven } \\
\text { fabric }\end{array}$ & $\begin{array}{l}\text { Suction } \\
\text { filtration }\end{array}$ & - & - & $\begin{array}{c}150 \\
(10 \% \text { strain })\end{array}$ & - & $\begin{array}{c}\text { Monitor human } \\
\text { wrist } \\
\text { movements }\end{array}$ & $\begin{array}{l}\text { Electrothermal } \\
\text { property (about } \\
50{ }^{\circ} \mathrm{C} \text { under a } \\
\text { voltage of } 6 \mathrm{~V} \text { ) }\end{array}$ & [86] \\
\hline Graphene & $\begin{array}{c}\text { Nonwoven } \\
\text { fabric }\end{array}$ & Spray coating & $\begin{array}{c}9(1 \% \text { strain }) \\
9.43(20 \% \text { strain })\end{array}$ & - & $\begin{array}{c}20 \\
(1-3 \% \text { strain })\end{array}$ & - & - & - & [73] \\
\hline RGO & $\begin{array}{c}\text { Nonwoven } \\
\text { fabric }\end{array}$ & Dip-and-reduce & $\begin{array}{c}-7.1 \\
(1 \% \text { strain }) \\
\end{array}$ & - & $\begin{array}{c}10,000 \\
(1 \% \text { strain }) \\
\end{array}$ & - & $\begin{array}{l}\text { Monitor human } \\
\text { motions }\end{array}$ & - & {$[71]$} \\
\hline $\begin{array}{l}\text { Graphene/ } \\
\text { cellulose } \\
\text { nanocrystal }\end{array}$ & $\begin{array}{l}\text { TPU non-woven } \\
\text { fabrics }\end{array}$ & Dip-coating & $\begin{array}{c}180 \\
\text { (15\% strain) }\end{array}$ & Up to 98 & $\begin{array}{c}>1000 \\
(10 \% \text { strain })\end{array}$ & 33 & $\begin{array}{c}\text { Detect } \\
\text { full-range } \\
\text { human activities }\end{array}$ & $\begin{array}{l}\text { Self-cleaning, } \\
\text { anti-corrosion } \\
\text { ability and } \\
\text { waterproofness } \\
\left(\mathrm{WCA}=154^{\circ}\right)\end{array}$ & [87] \\
\hline
\end{tabular}


(1) Preparation methods and performance.

Various methods, including screen-printing [85], suction filtration and reduction [86], spray coating [73], dip-and-reduce [71,72], dip-coating [87], etc., can be adopted to combine nonwoven fabric with graphene-based materials for making strain sensors with high sensitivity, good stability, and wide sensing range. In addition to the basic performance of the strain sensors, the as-prepared sensors also possess some other properties, like wash fastness [72,85], integrating into clothes [71], self-cleaning, anti-corrosion ability, and waterproofness [87].

(2) Relationship between GF absolute value and structure.

The crack of the materials is worth noting. Graphene-based sensors exhibit reversible and irreversible changes in resistance when subjected to strain. The reversible resistance change is relevant to strain sensing, so the strain used in the testing should not be excessive. High values of the GF may be due to the involvement of an irreversible resistance change. For example, Liu et al. [87] fabricate a strain sensor, which shows a GF of about 180 at $15 \%$ strain. Then, GF reaches up to be about 23,600 under $98 \%$ strain. This may be conducted by the crack or even fracture of the sensing material under large-strain deformation, which leads to the damage of the conductive grid and open circuit, so the GF will enlarge infinitely.

Currently, in graphene-based fabric strain sensors, the research on nonwoven fabric as the substrate is less than that on woven fabric as the substrate, which may be thanks to the poor strength of nonwoven fabric. For the nonwoven fabrics, the tensile strength is obviously lower in comparison with woven fabrics [73].

\subsubsection{Woven Fabric Strain Sensors}

Woven fabrics are made by interlacing warp and weft yarns according to certain rules $[112,113]$. They are endowed with good characteristics of structural stability and washing resistance. Graphene-based materials can be attached to woven fabrics in a variety of ways, for preparing graphene-based woven strain sensors with high sensitivity and stability. Liu et al. [77] prepare graphene woven fabric (GWF) via a CVD method. GWF owns high sensitivity (GF of 223 at a strain of 3\%), good stability, and low hysteresis. Liu et al. [76] also employ the same method to fabricate an elastomer-filled graphene woven fabric with a high GF (282 at $20 \%$ strain). Liu et al. use an ultraviolet picosecond laser technique to produce graphene strain sensors with high sensitivity [78].

The method of coating conductive solution or dispersion on woven fabrics is more widely used because of its simplicity and ease of operation. Yin et al. [88] make a strain sensor based on RGO woven fabrics through a dip-coating method. The strain sensor possesses a high GF (3667 within 48-57\% strain), an ultrafast response time, and good stretchability, durability, and stability. He et al. [81] fabricate a highly conductive silver/graphene-coated (Ag/G-coated) cotton fabric by dipping and magnetron sputtering. Zheng et al. [82] dip cotton fabric into graphene dispersion repeatedly for obtaining a strain sensor (CFSS) with good sensitivity and stability (10,000 cycles under $30 \%$ strain). In addition, the conductive solution can also be coated on woven fabrics by spin-coating [17] and spray coating [74].

Graphene-based woven fabric strain sensors can also be achieved by a vacuum filtration method. Ren et al. [80] employ a vacuum filtration method to manufacture a strain sensor, which possesses washability (sheet resistance changes from $\sim 0.9$ to $\sim 1.2 \mathrm{k} \Omega / \mathrm{sq}$ after 10 washing cycles). Wang et al. [79] use the same method to prepare a graphenesilk fabric strain sensor with excellent GF (about 124), stability, UV-blocking, and wash fastness properties.

The performance of various graphene-based woven strain sensors reported in the literature is presented in Table 4 . There are different methods to obtain graphene-based woven fabric sensors, such as CVD method [76,77], direct laser writing [78], dip-coating [81-83,88-92], spin-coating [17], spray coating [74], vacuum filtration [79,80], among others. Woven fabrics are excellent flexible substrates that can be well combined with graphene-based materials. The as-prepared strain sensors are endowed with good performance, including 
sensitivity, stability, sensing range, etc. Compared to staple fiber and filament strain sensors, woven fabric strain sensors have better washable resistance $[80,83,91]$, but their sensing range is small $[17,76,79]$, which may be because of their poor stretchability.

\subsubsection{Knitted Fabric Strain Sensors}

Knitted fabrics are made up of loops, possessing excellent elastic, softness, and comfort [114-116]. Mainly thanks to the existence of the winding loops that can expand in various directions, they can be highly stretched [93]. Knitted fabrics are regarded as ideal vehicles for strain sensors [94]. Graphene-based materials can be deposited on fabrics in a variety of ways. The dip-coating method is the most common method to prepare strain sensors with good performance. Hanna Lee et al. [94] obtain a strain sensor with good sensitivity (GF of 18.24 within $40.6 \%$ strain) by a dip-coating method. But the repeatability of the sensor is seldom provided. Zhang et al. [95] fabricate a graphene textile strain sensor with negative resistance variation through a dip-coating method. The sensor displays a maximum GF of -1.7 in the strain range of $15 \%$ during $x$-direction stretching and -26 within an $8 \%$ strain range with y-direction stretching. Ravinder Reddy $\mathrm{K}$ et al. [96] use the same method to prepare the RGO polyester knitted elastic band (RGOPEB) strain sensor, which exhibits excellent performance including great sensitivity, a low detection limit, and good durability and stability. Cai et al. [97] manufacture high sensitive strain sensing fabrics (FSSFs) with washability (resistance increased from $\sim 112 \mathrm{k} \Omega / \mathrm{m}^{2}$ to $\sim 154 \mathrm{k} \Omega / \mathrm{m}^{2}$ after 8 washing cycles). Graphene-based materials can also be combined with knitted fabric via spray coating [75], pad dyeing [84], etc. Xu et al. [84] pad-dyeing wool-knitted fabrics to prepare a rGO-based strain sensor, showing high sensitivity, low hysteresis, and great stability.

The properties of various graphene-based knitted strain sensors are presented in Table 5. Graphene-based knitted fabric sensors with prominent property can be realized by dip-coating [93-97], spray coating [75], pad dyeing [84], etc. Thanks to the unique structure of knitted fabrics, graphene-based fabric strain sensors possess resistance anisotropy [84,95]. The sensitivity of the prepared strain sensor in $x$-direction and y-direction is generally different. Therefore, the stretching direction of the strain sensor can be judged according to its resistance change. It is worth noting that there are positive and negative differences in GF values of graphene-based knitted strain sensors, which may be caused by different orientations. The sensitivity of the fabric strain sensor is independent of direction.

In summary, various approaches, including dip-coating [71,72,81-83,87-97], spray coating [73-75], spin-coating [17], CVD [76,77], vacuum filtration [79,80], suction filtration and reduction [86], screen-printing [85], direct laser writing [78], pad dyeing [84], etc., can be used to combine fabrics with graphene-based materials, with the purpose of fabricating strain sensors. Among them, the most widely used method to prepare strain sensor is to immerse the fabric in conductive solution or dispersion solution, which utilizes the water solubility and applicability of precursor GO. Most of the as-prepared graphene-based fabric sensors hold great sensitivity, stability, sensing range, etc. In addition, the strain sensor also possesses some other properties, like wear comfort [94], wash fastness [72,80,85,97], integrating into clothes $[71,79,84]$, self-cleaning, anti-corrosion ability [87], and waterproofness $[83,87,91]$. 
Table 4. Performance of various graphene-based woven strain sensors reported in the literature.

\begin{tabular}{|c|c|c|c|c|c|c|c|c|c|}
\hline $\begin{array}{c}\text { Main } \\
\text { Materials }\end{array}$ & Substrate & $\begin{array}{c}\text { Fabrication } \\
\text { Method }\end{array}$ & GF & $\begin{array}{c}\text { Sensing } \\
\text { Range (\%) }\end{array}$ & $\begin{array}{l}\text { Stability } \\
\text { (Cycle) }\end{array}$ & $\begin{array}{l}\text { Response } \\
\text { Time (ms) }\end{array}$ & Application & $\begin{array}{c}\text { Other } \\
\text { Advantages }\end{array}$ & References \\
\hline Graphene & Woven fabrics & CVD & $\begin{array}{c}\sim 223 \\
(3 \% \text { strain }) \\
\end{array}$ & - & 1000 & $\sim 72$ & $\begin{array}{c}\text { A wearable } \\
\text { musical instrument }\end{array}$ & - & {$[77]$} \\
\hline Graphene & Woven fabrics & CVD & $\begin{array}{c}70(10 \% \text { strain }) \\
282(20 \% \text { strain })\end{array}$ & Up to 30 & $\begin{array}{c}>4000 \\
(5 \% \text { and } 50 \% \\
\text { strain) }\end{array}$ & $\sim 70$ & $\begin{array}{c}\text { Detect } \\
\text { physiological motions }\end{array}$ & - & [76] \\
\hline $\mathrm{GO}$ & Polyimide fabric & $\begin{array}{l}\text { Direct laser } \\
\text { writing }\end{array}$ & $\begin{array}{c}27 \\
(0-4 \% \text { strain })\end{array}$ & - & $\begin{array}{c}1000 \\
(4 \% \text { strain })\end{array}$ & - & Detect human motion & - & [78] \\
\hline RGO & Cotton bandage & Dip-coating & $\begin{array}{c}416 \\
(0-40 \% \text { strain }) \\
3667 \\
\text { (48-57\% strain) } \\
\end{array}$ & Up to 57 & $\begin{array}{c}>1000(0-7.5 \% \\
0-15 \%, 0-30 \%, \\
0-45 \% \text { strain })\end{array}$ & $<20$ & $\begin{array}{l}\text { Monitor a wide range } \\
\text { of human activities }\end{array}$ & - & [88] \\
\hline Graphene & Cotton fabric & Dipping & $\begin{array}{c}2.49 \\
(30 \% \text { strain })\end{array}$ & $0-75$ & $\begin{array}{c}10,000 \\
(30 \% \text { strain })\end{array}$ & $\sim 90$ & $\begin{array}{l}\text { Detect the finger } \\
\text { motion, book folding, } \\
\text { ruler oscillating } \\
\text { vibration, and phone } \\
\text { speaker vibration }\end{array}$ & - & {$[82]$} \\
\hline $\begin{array}{l}\text { Graphene } \\
\text { nanoplatelets / } \\
\text { polyaniline }\end{array}$ & Lycra fabric & Spin-coating & $\begin{array}{c}\sim 67 \\
(0-40 \% \text { strain })\end{array}$ & Up to 40 & $\begin{array}{c}1500(5 \% \text { and } 9 \% \\
\text { strain) }\end{array}$ & - & $\begin{array}{l}\text { Monitor the movement } \\
\text { of five fingers }\end{array}$ & - & [17] \\
\hline RGO & Cotton fabric & Dip and reduce & $\begin{array}{c}4 \\
\text { (3.3-5.5\% strain) }\end{array}$ & - & $\begin{array}{c}100,000 \\
\text { (11.6\% strain) }\end{array}$ & - & $\begin{array}{l}\text { Monitor human } \\
\text { movements }\end{array}$ & Waterproof properties & [83] \\
\hline RGO & $\begin{array}{l}\text { An elastic fabric } \\
\text { composed of } \\
\text { polyurethane } \\
\text { and polyester }\end{array}$ & Dip-coating & $\begin{array}{c}4.13 \\
(0-30 \% \text { strain })\end{array}$ & - & $\begin{array}{c}1000 \\
(20 \% \text { strain })\end{array}$ & - & $\begin{array}{l}\text { Monitor a full range of } \\
\text { human activities }\end{array}$ & $\begin{array}{l}\text { Water-resistant and } \\
\text { skin-adhesive }\end{array}$ & [91] \\
\hline RGO & Cotton fabric & $\begin{array}{l}\text { Vacuum } \\
\text { filtration }\end{array}$ & - & - & 400 & - & $\begin{array}{l}\text { Monitor the wrist } \\
\text { bending }\end{array}$ & $\begin{array}{l}\text { Washability (sheet } \\
\text { resistance changes from } \\
\sim 0.9 \text { to } \sim 1.2 \mathrm{k} \Omega / \text { sq after } \\
10 \text { washing cycles) }\end{array}$ & {$[80]$} \\
\hline RGO & Silk fabric & $\begin{array}{l}\text { Vacuum } \\
\text { filtration }\end{array}$ & $\begin{array}{c}124 \\
(10 \% \text { strain })\end{array}$ & $\sim 10$ & $\begin{array}{c}1000 \\
(2 \% \text { strain })\end{array}$ & - & Detect human motions & $\begin{array}{c}\text { UV-blocking and } \\
\text { hydrophobicity } \\
\text { properties }\end{array}$ & [79] \\
\hline
\end{tabular}


Table 5. Properties of various graphene-based knitted strain sensors.

\begin{tabular}{|c|c|c|c|c|c|c|c|c|c|}
\hline Main Materials & Substrate & $\begin{array}{c}\text { Fabrication } \\
\text { Method }\end{array}$ & GF & $\begin{array}{c}\text { Sensing Range } \\
(\%)\end{array}$ & $\begin{array}{l}\text { Stability } \\
\text { (Cycle) }\end{array}$ & $\begin{array}{c}\text { Response Time } \\
\text { (ms) }\end{array}$ & Application & $\begin{array}{c}\text { Other } \\
\text { Advantages }\end{array}$ & References \\
\hline RGO & $\begin{array}{l}\text { Spandex/nylon } \\
\text { knitted fabric }\end{array}$ & Dip-coating & $\begin{array}{c}\sim 18.5 \\
(<40.6 \% \text { strain })\end{array}$ & - & - & - & $\begin{array}{l}\text { Monitor body } \\
\text { movements }\end{array}$ & - & [94] \\
\hline RGO & $\begin{array}{c}\text { Weft-knit } \\
\text { polyester fabric }\end{array}$ & Dip-coating & $\begin{array}{c}-1.7 \\
(<15 \% \text { strain, } \\
\text { x-direction) } \\
-26(<8 \% \text { strain, } \\
\text { y-direction) }\end{array}$ & Up to 50 & $\begin{array}{c}500 \text { ( } 7.5 \% \text { strain, } \\
\text { x-direction) } 500 \\
\text { (5\% strain, } \\
\text { y-direction) }\end{array}$ & - & $\begin{array}{l}\text { Detect the } \\
\text { physiological } \\
\text { activity of } \\
\text { human body }\end{array}$ & - & [95] \\
\hline RGO & $\begin{array}{l}\text { Polyester } \\
\text { knitted } \\
\text { elastic band }\end{array}$ & Dip-coating & $\begin{array}{c}34(0-20 \% \text { strain }) \\
5(20-50 \% \\
\text { strain })\end{array}$ & $0.2-50$ & $\begin{array}{c}>6000 \\
(30 \% \text { strain })\end{array}$ & - & $\begin{array}{l}\text { Monitoring of } \\
\text { large scale as } \\
\text { well as } \\
\text { small-scale } \\
\text { human body } \\
\text { motions }\end{array}$ & - & [96] \\
\hline RGO & $\begin{array}{l}\text { Nylon/ } \\
\text { polyurethane } \\
\text { fabric }\end{array}$ & Dip-coating & $\begin{array}{l}18.5(0-10 \% \\
\text { strain }) \\
12.1(10-18 \% \\
\text { strain) }\end{array}$ & $0-33$ & $\begin{array}{c}120 \\
\text { (3\% strain) }\end{array}$ & - & $\begin{array}{l}\text { Monitor human } \\
\text { motions }\end{array}$ & $\begin{array}{c}\text { Washability } \\
\text { (resistance } \\
\text { increased from } \\
\sim 112 \mathrm{k} \Omega / \mathrm{m}^{2} \text { to } \\
\sim 154 \mathrm{k} \Omega / \mathrm{m}^{2} \\
\text { after } 8 \\
\text { washing cycles) }\end{array}$ & [97] \\
\hline RGO & $\begin{array}{l}\text { Wool-knitted } \\
\text { fabric }\end{array}$ & Pad-dyeing & $\begin{array}{l}0.9 \text { (20\% strain, } \\
\text { x-direction) } \\
3 \text { (20\% strain, } \\
\text { y-direction) }\end{array}$ & Up to 40 & $\begin{array}{c}500 \\
\text { (20\% strain, } \\
\text { y-direction) }\end{array}$ & - & $\begin{array}{l}\text { Detect human } \\
\text { respiration } \\
\text { movements and } \\
\text { large motions }\end{array}$ & $\begin{array}{c}\text { Seamlessly } \\
\text { integrate with } \\
\text { other fabric } \\
\text { materials }\end{array}$ & [84] \\
\hline
\end{tabular}




\section{Applications}

Based on the excellent performance of graphene-based textile strain sensors, they can be applied in various fields. Strain sensors are mainly used for detecting human motion. Human motions monitoring can be categorized as large human motions (walking, joint motion, finger bending, etc.) and subtle physiological motions (respiration, phonation, pulse wave, etc.) $[45,46,50-52,57-59,61,62,64-66,68,70-72,76,78-80,83-88,91,94-97]$, as illustrated in Figure 4a-d. Graphene-based textile strain sensors are usually attached to different body parts, such as knees, fingers, elbows, eyes, mouth, etc., for sensing body movements. Cai et al. [97] attached a knitted fabric strain sensor to a body for monitoring human motions, including the flexion and rotation of the wrist and bending of fingers. Huang et al. [57] prepared a strain sensor, which can monitor a pulse wave, and eyeball movement, while keeping comfortable wearing sense. At present, most graphene-based textile strain sensors can be successfully applied to real-time monitoring of human motions. However, strain sensors are usually attached to body parts to sense movements of the human body, which are called "wearable". It is still a challenge to develop stable and truly wearable graphene-based textile strain sensors.
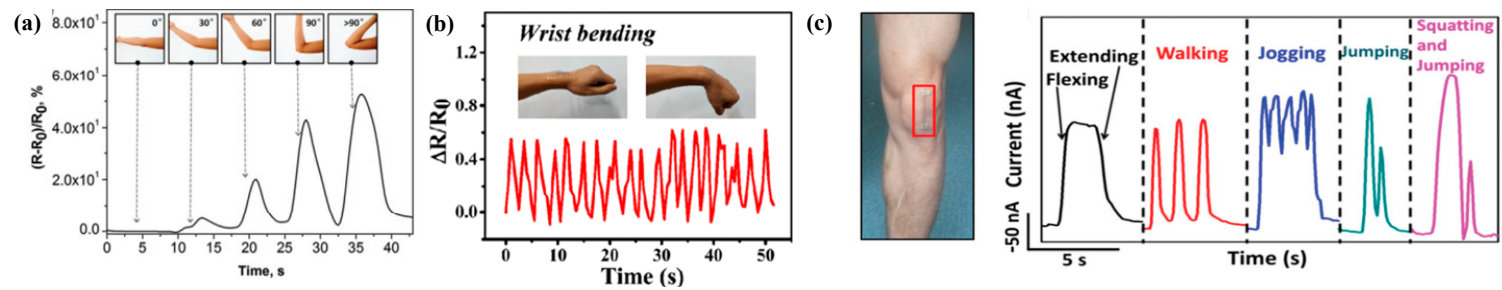

(d)
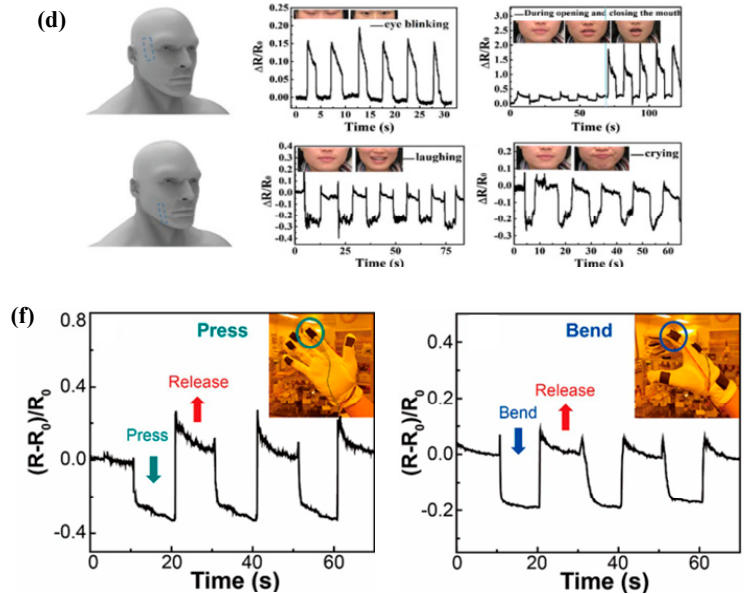

(e)
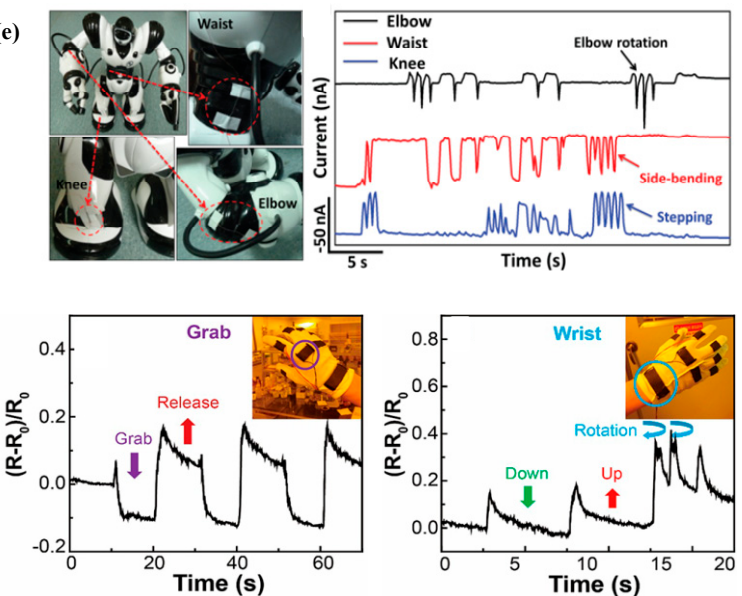

Figure 4. Applications of graphene-based textile strain sensors. (a) Relative resistance changes of the elbow joint bending. "Adapted with permission from reference [45]. Copyright [2020], Macromolecular Materials and Engineering". (b) Relative resistance changes of the CFSS to wrist bending. "Adapted with permission from reference [82]. Copyright [2020], ACS Applied Materials \& Interfaces". (c) Responsive curves of wearable sensor on the knee under motions of flexing/extending, walking, jogging, jumping, and squatting-jumping. "Adapted with permission from reference [65]. Copyright [2015], Advanced materials". (d) Responsive curves of the graphene-silk fabric strain sensor to eyes blinking, mouth opening and closing, laughing and crying. "Adapted with permission from reference [79]. Copyright [2019], Advanced Materials Interfaces". (e) Responsive curves of wearable sensors during the robot's dance "Gangnam Style": Elbow (black line), waist (redline), and knee (blue line). "Adapted with permission from reference [65]. Copyright [2015], Advanced materials". (f) Relative resistance changes with various movements of the motion glove containing the fabric-based sensors, such as pressing, bending, grabbing, and up, down, and rotation of the wrist. "Adapted with permission from reference [83]. Copyright [2018], ACS Applied Materials \& Interfaces".

Strain sensors can also be applied to complex robot detection and entertainment $[65,77]$, as shown in Figure 4e. Cheng et al. [65] fabricated a yarn strain sensor, which not only 
can monitor a wide variety of human activities, including sleep, talk, pulse beat, walk, jog, jump, but also can detect and record of complex robot movements. Liu et al. [77] synthesized graphene woven fabric strain sensor, which can be used to create a wearable musical instrument. It allows the users to manipulate music through small body movements.

In addition, multiple strain sensors can be glued or woven into gloves to sense hand movements (Figure 4f) [83]. When the measured object moves, strain sensors deform. The electrical signal of sensors changes, resulting in sensing phenomenon.

\section{Conclusions and Outlook}

In this review, a variety of graphene-based textile strain sensors are evaluated comprehensively. The preparation methods, performance, and applications of textile strain sensors, including staple fiber, staple and filament yarn, nonwoven fabric, woven fabric, and knitted fabric strain sensors, are analyzed and discussed.

\subsection{Challenges and Pitfalls}

In spite of the graphene-based textile strain sensors having good performance, they face many challenges and pitfalls. First of all, the application capacity of graphene-based textile strain sensors is limited. Most researches only consider sensors water resistance, but do not consider the impact of other environmental factors, such as friction, $\mathrm{PH}$, etc. Secondly, fiber/yarn strain sensors need flexible substrates such as PDMS [49,54,55,57,62,64,65], Ecoflex [58,59], or TPU [51] to protect their structure because sensing fibers and yarns are easily damaged, which may not achieve comfort in practical application. In addition, most sensors are attached to human skin to pick up signals. Although the sensitivity is high, the comfort is poor. Designing graphene-based fibers and yarns strain sensors with satisfactory comfort remains a big challenge. Thirdly, graphene-based textile strain sensors have good sensitivity and tensile properties, but it is difficult to achieve both high sensitivity and high tensile properties. Fourth, most of the resistance measurements are made using the twoprobe method rather than the four-probe method, so that the contact resistance is included in the measurement resistance. During the strain process, both the contact resistance and sample resistance will change. The resistance obtained by using the four-probe method is more sensitive and more precise than that obtained by using the two-probe method, which can accurately reflect the damage of the sensing material caused by strain [117]. What is more, the nonlinear relationship prevails in textile strain sensors, but some articles do not properly deal with the nonlinear relationship between GF and strain $[60,62]$.

\subsection{Outlook}

In general, graphene-based textile strain sensors can be obtained in two ways. One is to prepare conductive textiles through spinning and weaving techniques. The other is to deposit graphene-based materials on the surface of textiles. Due to the solubility and applicability of GO, most strain sensors are prepared by dip-coating method [64-70,87-97], which is simple and easy to operate regardless of the complexity of the preparation process, but the resulting pollution of GO manufacturing is of concern (That is, to prepare one gram of GO will consume at least $1000 \mathrm{~g}$ of water.).

Most of graphene-based textile strain sensors possess good sensitivity, stability, and sensing range. However, compared to staple fiber and filament strain sensor, fabric sensors attracted more attention in functionality and practical application, such as wear comfort [94], good wash fastness [72,80,85,97], easily integrating into clothes [71,79,84], self-cleaning, anti-corrosion ability [87], and waterproofness [83,87,91].

With the increase of strain range, the GF absolute value of graphene-based textile strain sensors usually presents two different variation trends. One is that GF decreases with the increase of strain $[44,45,57,65,66,70]$; the other is that GF increases with the increase of strain $[59,68]$. According to the structure of graphene-based textile strain sensors, when a small strain is applied, its GF value decreases with the increase of strain, which may be due to the decrease of contact points between fibers. When the strain exceeds the allowable 
range of fibers, the conductive networks of the textile surface break and irreversible damage occurs, leading to a sharp change in its resistance and a rapid rise in GF. Under a huge strain, the sensing material will crack or even fracture, leading to the infinite increase of GF. Therefore, the stretching stage of graphene-based textile strain sensors, which correspond to the structural change of textiles, can be judged according to the variation trend of GF value. In addition, the nonlinear relationship prevails in textile strain sensors, although all the sensing linear relationship is within a certain range. It can be found that due to the slip inside the fiber or fabric and the change of textile strain sensor structure, the GF value of most textile strain sensors presents a nonlinear relationship with the strain. GF is the relative resistance that changes with strain. Therefore, the strain range applicable to GF values should be indicated.

In conclusion, in future studies, the effects of environmental factors such as friction and $\mathrm{pH}$ on the performance of graphene-based textile strain sensors are of concern. The nonlinear relationship of graphene-based textile strain sensors should be properly handled. Meanwhile, the GF value of strain sensors should be clearly analyzed to avoid misunderstanding. Moreover, in the test method, the four-probe method can be used more to measure resistance in order to avoid the impact of contact resistance on the experimental results.

Author Contributions: Conceptualization, R.Y. and X.H.; data curation, R.Y. and X.H.; writingoriginal draft preparation, R.Y. and X.H.; writing — review and editing, C.Z., J.W. and Y.L. All authors have read and agreed to the published version of the manuscript.

Funding: This research was funded by the National Natural Science Foundation of China (NSFC 51803185), Public Welfare Project of Zhejiang Province (LGF21E030005), China Postdoctoral Science Foundation (2020M681917), Postdoctoral Foundation of Zhejiang Sci-Tech University Tongxiang Research Institute (TYY202013), the Science Foundation of Zhejiang Sci-Tech University (No. 18012107-Y).

Conflicts of Interest: The authors declare no conflict of interest.

\section{References}

1. Wang, P.; Wei, W.; Li, Z.; Duan, W.; Han, H.; Xie, Q. A superhydrophobic fluorinated PDMS composite as a wearable strain sensor with excellent mechanical robustness and liquid impalement resistance. J. Mater. Chem. A 2020, 8, 3509-3516. [CrossRef]

2. Filippidou, M.; Tegou, E.; Tsouti, V.; Chatzandroulis, S. A flexible strain sensor made of graphene nanoplatelets/ polydimethylsiloxane nanocomposite. Microelectron. Eng. 2015, 142, 7-11. [CrossRef]

3. Seyedin, S.; Razal, J.M.; Innis, P.C.; Jeiranikhameneh, A.; Beirne, S.; Wallace, G.G. Knitted Strain Sensor Textiles of Highly Conductive All-Polymeric Fibers. ACS Appl. Mater. Interfaces 2015, 7, 21150-21158. [CrossRef] [PubMed]

4. Jeong, S.Y.; Ma, Y.W.; Lee, J.U.; Je, G.J.; Shin, B. Flexible and Highly Sensitive Strain Sensor Based on Laser-Induced Graphene Pattern Fabricated by 355 nm Pulsed Laser. Sensors 2019, 19, 4867. [CrossRef] [PubMed]

5. $\quad$ Chong, Y.S.; Yeoh, K.H.; Leow, P.L.; Chee, P.S. Piezoresistive strain sensor array using polydimethylsiloxane-based conducting nanocomposites for electronic skin application. Sens. Rev. 2018, 38, 494-500. [CrossRef]

6. Zhao, Y.; Huang, Y.; Hu, W.; Guo, X.; Wang, Y.; Liu, P.; Liu, C.; Zhang, Y. Highly sensitive flexible strain sensor based on threadlike spandex substrate coating with conductive nanocomposites for wearable electronic skin. Smart Mater. Struct. 2019, $28,035004$. [CrossRef]

7. Yang, T.; Wang, W.; Zhang, H.; Li, X.; Shi, J.; He, Y.; Zheng, Q.-S.; Li, Z.; Zhu, H. Tactile Sensing System Based on Arrays of Graphene Woven Microfabrics: Electromechanical Behavior and Electronic Skin Application. ACS Nano 2015, 9, 10867-10875. [CrossRef]

8. Ye, X.; Yuan, Z.; Tai, H.; Li, W.; Du, X.; Jiang, Y. A wearable and highly sensitive strain sensor based on a polyethylenimine-rGO layered nanocomposite thin film. J. Mater. Chem. C 2017, 5, 7746-7752. [CrossRef]

9. Liao, X.; Liao, Q.; Yan, X.; Liang, Q.; Si, H.; Li, M.; Wu, H.; Cao, S.; Zhang, Y. Flexible and Highly Sensitive Strain Sensors Fabricated by Pencil Drawn for Wearable Monitor. Adv. Funct. Mater. 2015, 25, 2395-2401. [CrossRef]

10. Qian, Q.; Wang, Y.; Zhang, M.; Chen, L.; Feng, J.; Wang, Y.; Zhou, Y. Ultrasensitive paper-based polyaniline/graphene composite strain sensor for sign language expression. Compos. Sci. Technol. 2019, 181, 107660. [CrossRef]

11. Wang, C.; Xia, K.; Jian, M.; Wang, H.; Zhang, M.; Zhang, Y. Carbonized silk georgette as an ultrasensitive wearable strain sensor for full-range human activity monitoring. J. Mater. Chem. C 2017, 5, 7604-7611. [CrossRef]

12. Zhang, M.; Wang, C.; Wang, H.; Jian, M.; Hao, X.; Zhang, Y. Carbonized Cotton Fabric for High-Performance Wearable Strain Sensors. Adv. Funct. Mater. 2017, 27, 1604795. [CrossRef] 
13. Yang, Y.F.; Tao, L.Q.; Pang, Y.; Tian, H.; Ju, Z.Y.; Wu, X.M.; Ren, T.L. An ultrasensitive strain sensor with a wide strain range based on graphene armour scales. Nanoscale 2018, 10, 11524-11530. [CrossRef] [PubMed]

14. Cai, Y.; Qin, J.; Li, W.; Tyagi, A.; Liu, Z.; Hossain, D.; Chen, H.; Kim, J.-K.; Liu, H.; Zhuang, M.; et al. A stretchable, conformable, and biocompatible graphene strain sensor based on a structured hydrogel for clinical application. J. Mater. Chem. A 2019, 7, 27099-27109. [CrossRef]

15. Pang, Y.; Tian, H.; Tao, L.; Li, Y.; Wang, X.; Deng, N.; Yang, Y.; Ren, T.L. Flexible, Highly Sensitive, and Wearable Pressure and Strain Sensors with Graphene Porous Network Structure. ACS Appl. Mater. Interfaces 2016, 8, 26458-26462. [CrossRef]

16. Zhang, M.; Wang, C.; Wang, Q.; Jian, M.; Zhang, Y. Sheath-Core Graphite/Silk Fiber Made by Dry-Meyer-Rod-Coating for Wearable Strain Sensors. ACS Appl. Mater. Interfaces 2016, 8, 20894-20899. [CrossRef]

17. Huang, Y.; Gao, L.; Zhao, Y.; Guo, X.; Liu, C.; Liu, P. Highly flexible fabric strain sensor based on graphene nanoplatelet-polyaniline nanocomposites for human gesture recognition. J. Appl. Polym. Sci. 2017, 134, 45340. [CrossRef]

18. Chung, D. Carbon materials for structural self-sensing, electromagnetic shielding and thermal interfacing. Carbon 2012, 50, 3342-3353. [CrossRef]

19. Alaferdov, A.V.; Savu, R.; Rackauskas, T.A.; Rackauskas, S.; Canesqui, M.A.; De Lara, D.S.; Setti, G.O.; Joanni, E.; De Trindade, G.M.; Lima, U.B.; et al. A wearable, highly stable, strain and bending sensor based on high aspect ratio graphite nanobelts. Nanotechnology 2016, 27, 375501. [CrossRef]

20. Tang, W.; Yan, T.; Wang, F.; Yang, J.; Wu, J.; Zhu, W.; Yue, T.; Li, Z. Rapid fabrication of wearable carbon nanotube/graphite strain sensor for real-time monitoring of plant growth. Carbon 2019, 147, 295-302. [CrossRef]

21. Guo, X.; Huang, Y.; Zhao, Y.; Mao, L.; Gao, L.; Pan, W.; Zhang, Y.; Liu, P. Highly stretchable strain sensor based on SWCNTs/CB synergistic conductive network for wearable human-activity monitoring and recognition. Smart Mater. Struct. 2017, $26,095017$. [CrossRef]

22. Chang, X.; Sun, S.; Sun, S.; Liu, T.; Xiong, X.; Lei, Y.; Dong, L.; Yin, Y. ZnO nanorods/carbon black-based flexible strain sensor for detecting human motions. J. Alloy. Compd. 2018, 738, 111-117. [CrossRef]

23. Zhang, F.; Wu, S.; Peng, S.; Wang, C.H. The effect of dual-scale carbon fibre network on sensitivity and stretchability of wearable sensors. Compos. Sci. Technol. 2018, 165, 131-139. [CrossRef]

24. Zhang, C.; Li, H.; Huang, A.; Zhang, Q.; Rui, K.; Lin, H.; Sun, G.; Zhu, J.; Peng, H.; Huang, W. Rational Design of a Flexible CNTs@PDMS Film Patterned by Bio-Inspired Templates as a Strain Sensor and Supercapacitor. Small 2019, 15, e1805493. [CrossRef] [PubMed]

25. Lu, L.; Zhou, Y.; Pan, J.; Chen, T.; Hu, Y.; Zheng, G.; Dai, K.; Liu, C.; Shen, C.; Sun, X.; et al. Design of Helically Double-Leveled Gaps for Stretchable Fiber Strain Sensor with Ultralow Detection Limit, Broad Sensing Range, and High Repeatability. ACS Appl. Mater. Interfaces 2019, 11, 4345-4352. [CrossRef]

26. Ryu, S.; Lee, P.; Chou, J.B.; Xu, R.; Zhao, R.; Hart, A.J.; Kim, S.-G. Extremely Elastic Wearable Carbon Nanotube Fiber Strain Sensor for Monitoring of Human Motion. ACS Nano 2015, 9, 5929-5936. [CrossRef]

27. Chen, Y.; Xu, B.; Gong, J.; Wen, J.; Hua, T.; Kan, C.W.; Deng, J. Design of High-Performance Wearable Energy and Sensor Electronics from Fiber Materials. ACS Appl. Mater. Interfaces 2019, 11, 2120-2129. [CrossRef]

28. Qi, X.; Li, X.; Jo, H.; Bhat, K.S.; Kim, S.H.; An, J.; Kang, J.-W.; Lim, S. Mulberry paper-based graphene strain sensor for wearable electronics with high mechanical strength. Sens. Actuators A Phys. 2020, 301, 111697. [CrossRef]

29. Yang, Y.; Cao, Z.; He, P.; Shi, L.; Ding, G.; Wang, R.; Sun, J. Ti3C2Tx MXene-graphene composite films for wearable strain sensors featured with high sensitivity and large range of linear response. Nano Energy 2019, 66, 104134. [CrossRef]

30. Sun, S.; Liu, Y.; Chang, X.; Jiang, Y.; Wang, D.; Tang, C.; He, S.; Wang, M.; Guo, L.; Gao, Y. A wearable, waterproof, and highly sensitive strain sensor based on three-dimensional graphene/carbon black/Ni sponge for wirelessly monitoring human motions. J. Mater. Chem. C 2020, 8, 2074-2085. [CrossRef]

31. Cheng, H.; Dong, Z.; Hu, C.; Zhao, Y.; Hu, Y.; Qu, L.; Chen, N.; Dai, L. Textile electrodes woven by carbon nanotube-graphene hybrid fibers for flexible electrochemical capacitors. Nanoscale 2013, 5, 3428-3434. [CrossRef] [PubMed]

32. Liu, Y.; Xia, L.; Zhang, Q.; Guo, H.; Wang, A.; Xu, W.; Wang, Y. Structure and properties of carboxymethyl cotton fabric loaded by reduced graphene oxide. Carbohydr. Polym. 2019, 214, 117-123. [CrossRef] [PubMed]

33. Xu, R.; Lu, Y.; Jiang, C.; Chen, J.; Mao, P.; Gao, G.; Zhang, L.; Wu, S. Facile Fabrication of Three-Dimensional Graphene Foam/Poly(dimethylsiloxane) Composites and Their Potential Application as Strain Sensor. ACS Appl. Mater. Interfaces 2014, 6, 13455-13460. [CrossRef] [PubMed]

34. Ling, S.; Wang, Q.; Zhang, D.; Zhang, Y.; Mu, X.; Kaplan, D.L.; Buehler, M.J. Integration of Stiff Graphene and Tough Silk for the Design and Fabrication of Versatile Electronic Materials. Adv. Funct. Mater. 2017, 28, 28. [CrossRef]

35. Novoselov, K.S.; Geim, A.K.; Morozov, S.V.; Jiang, D.; Zhang, Y.; Dubonos, S.V.; Grigorieva, I.V.; Firsov, A.A. Electric Field Effect in Atomically Thin Carbon Films. Science 2004, 306, 666-669. [CrossRef]

36. Balandin, A.A.; Ghosh, S.; Bao, W.; Calizo, I.; Teweldebrhan, D.; Miao, F.; Lau, C.N. Superior Thermal Conductivity of Single-Layer Graphene. Nano Lett. 2008, 8, 902-907. [CrossRef]

37. Liu, Y.; Zhang, D.; Wang, K.; Liu, Y.; Shang, Y. A novel strain sensor based on graphene composite films with layered structure. Compos. Part A Appl. Sci. Manuf. 2016, 80, 95-103. [CrossRef]

38. Liu, H.; Li, Y.; Dai, K.; Zheng, G.; Liu, C.; Shen, C.; Yan, X.; Guo, J.; Guo, Z. Electrically conductive thermoplastic elastomer nanocomposites at ultralow graphene loading levels for strain sensor applications. J. Mater. Chem. C 2016, 4, 157-166. [CrossRef] 
39. Huang, S.; He, G.; Yang, C.; Wu, J.; Guo, C.; Hang, T.; Li, B.; Yang, C.; Liu, D.; Chen, H.-J.; et al. Stretchable Strain Vector Sensor Based on Parallelly Aligned Vertical Graphene. ACS Appl. Mater. Interfaces 2018, 11, 1294-1302. [CrossRef]

40. Meng, Q.; Liu, Z.; Han, S.; Xu, L.; Araby, S.; Cai, R.; Zhao, Y.; Lu, S.; Liu, T. A facile approach to fabricate highly sensitive, flexible strain sensor based on elastomeric/graphene platelet composite film. J. Mater. Sci. 2019, 54, 10856-10870. [CrossRef]

41. Jost, K.; Dion, G.; Gogotsi, Y. Textile energy storage in perspective. J. Mater. Chem. A 2014, 2, 10776-10787. [CrossRef]

42. Shao, F.; Bian, S.-W.; Zhu, Q.; Guo, M.-X.; Liu, S.; Peng, Y.-H. Fabrication of Polyaniline/Graphene/Polyester Textile Electrode Materials for Flexible Supercapacitors with High Capacitance and Cycling Stability. Chem. Asian J. 2016, 11, 1906-1912. [CrossRef] [PubMed]

43. Yun, T.G.; Hwang, B.I.; Kim, D.; Hyun, S.; Han, S.M. Polypyrrole-MnO2-Coated Textile-Based Flexible-Stretchable Supercapacitor with High Electrochemical and Mechanical Reliability. ACS Appl. Mater. Interfaces 2015, 7, 9228-9234. [CrossRef] [PubMed]

44. Wang, X.; Meng, S.; Tebyetekerwa, M.; Li, Y.; Pionteck, J.; Sun, B.; Qin, Z.; Zhu, M. Highly sensitive and stretchable piezoresistive strain sensor based on conductive poly(styrene-butadiene-styrene)/few layer graphene composite fiber. Compos. Part A Appl. Sci. Manuf. 2018, 105, 291-299. [CrossRef]

45. Li, W.; Zhou, Y.; Wang, Y.; Li, Y.; Jiang, L.; Ma, J.; Chen, S. Highly Stretchable and Sensitive SBS/Graphene Composite Fiber for Strain Sensors. Macromol. Mater. Eng. 2020, 305, 1900736. [CrossRef]

46. Jiang, X.; Ren, Z.; Fu, Y.; Liu, Y.; Zou, R.; Ji, G.; Ning, H.; Li, Y.; Wen, J.; Qi, H.J.; et al. Highly Compressible and Sensitive Pressure Sensor under Large Strain Based on 3D Porous Reduced Graphene Oxide Fiber Fabrics in Wide Compression Strains. ACS Appl. Mater. Interfaces 2019, 11, 37051-37059. [CrossRef]

47. Kim, S.W.; Kwon, S.N.; Na, S.I. Stretchable and electrically conductive polyurethane- silver/graphene composite fibers prepared by wet-spinning process. Compos. Part B: Eng. 2019, 167, 573-581. [CrossRef]

48. Chen, J.; Wen, H.; Zhang, G.; Lei, F.; Feng, Q.; Liu, Y.; Cao, X.; Dong, H. Multifunctional Conductive Hydrogel/Thermochromic Elastomer Hybrid Fibers with a Core-Shell Segmental Configuration for Wearable Strain and Temperature Sensors. ACS Appl. Mater. Interfaces 2020, 12, 7565-7574. [CrossRef]

49. Liu, F.; Dong, Y.; Shi, R.; Wang, E.; Ni, Q.; Fu, Y. Continuous graphene fibers prepared by liquid crystal spinning as strain sensors for Monitoring Vital Signs. Mater. Today Commun. 2020, 24, 100909. [CrossRef]

50. Li, G.; Dai, K.; Ren, M.; Wang, Y.; Zheng, G.; Liu, C.; Shen, C. Aligned flexible conductive fibrous networks for highly sensitive, ultrastretchable and wearable strain sensors. J. Mater. Chem. C 2018, 6, 6575-6583. [CrossRef]

51. Yan, T.; Wang, Z.; Wang, Y.Q.; Pan, Z. Carbon/graphene composite nanofiber yarns for highly sensitive strain sensors. Mater. Des. 2018, 143, 214-223. [CrossRef]

52. Nan, N.; He, J.; You, X.; Sun, X.; Zhou, Y.; Qi, K.; Shao, W.; Liu, F.; Chu, Y.; Ding, B. A Stretchable, Highly Sensitive, and Multimodal Mechanical Fabric Sensor Based on Electrospun Conductive Nanofiber Yarn for Wearable Electronics. Adv. Mater. Technol. 2018, 4, 1800338. [CrossRef]

53. You, X.; He, J.; Nan, N.; Sun, X.; Qi, K.; Zhou, Y.; Shao, W.; Liu, F.; Cui, S. Stretchable capacitive fabric electronic skin woven by electrospun nanofiber coated yarns for detecting tactile and multimodal mechanical stimuli. J. Mater. Chem. C 2018, 6, 12981-12991. [CrossRef]

54. Wang, X.; Qiu, Y.; Cao, W.; Hu, P. Highly Stretchable and Conductive Core-Sheath Chemical Vapor Deposition Graphene Fibers and Their Applications in Safe Strain Sensors. Chem. Mater. 2015, 27, 6969-6975. [CrossRef]

55. Nakamura, A.; Hamanishi, T.; Kawakami, S.; Takeda, M. A piezo-resistive graphene strain sensor with a hollow cylindrical geometry. Mater. Sci. Eng. B 2017, 219, 20-27. [CrossRef]

56. Chu, J.; Marsden, A.J.; Young, R.J.; Bissett, M.A. Graphene-Based Materials as Strain Sensors in Glass Fiber/Epoxy Model Composites. ACS Appl. Mater. Interfaces 2019, 11, 31338-31345. [CrossRef]

57. Huang, T.; He, P.; Wang, R.; Yang, S.; Sun, J.; Xie, X.; Ding, G. Porous Fibers Composed of Polymer Nanoball Decorated Graphene for Wearable and Highly Sensitive Strain Sensors. Adv. Funct. Mater. 2019, 29, 1903732. [CrossRef]

58. Souri, H.; Bhattacharyya, D. Wearable strain sensors based on electrically conductive natural fiber yarns. Mater. Des. 2018, 154, 217-227. [CrossRef]

59. Souri, H.; Bhattacharyya, D. Highly stretchable and wearable strain sensors using conductive wool yarns with controllable sensitivity. Sens. Actuators A Phys. 2019, 285, 142-148. [CrossRef]

60. Li, X.; Hua, T.; Xu, B. Electromechanical properties of a yarn strain sensor with graphene-sheath/polyurethane-core. Carbon 2017, 118, 686-698. [CrossRef]

61. Li, X.; Hu, H.; Hua, T.; Xu, B.; Jiang, S. Wearable strain sensing textile based on one-dimensional stretchable and weavable yarn sensors. Nano Res. 2018, 11, 5799-5811. [CrossRef]

62. Park, J.J.; Hyun, W.J.; Mun, S.C.; Park, Y.T.; Park, O.O. Highly Stretchable and Wearable Graphene Strain Sensors with Controllable Sensitivity for Human Motion Monitoring. ACS Appl. Mater. Interfaces 2015, 7, 6317-6324. [CrossRef] [PubMed]

63. Li, X.; Koh, K.H.; Farhan, M.; Lai, K.W.C. An ultraflexible polyurethane yarn-based wearable strain sensor with a polydimethylsiloxane infiltrated multilayer sheath for smart textiles. Nanoscale 2020, 12, 4110-4118. [CrossRef] [PubMed]

64. Yin, F.; Li, X.; Peng, H.; Li, F.; Yang, K.; Yuan, W. A highly sensitive, multifunctional, and wearable mechanical sensor based on RGO/synergetic fiber bundles for monitoring human actions and physiological signals. Sens. Actuators B Chem. 2019, 285, 179-185. [CrossRef] 
65. Cheng, Y.; Wang, R.; Sun, J.; Gao, L. A Stretchable and Highly Sensitive Graphene-Based Fiber for Sensing Tensile Strain, Bending, and Torsion. Adv. Mater. 2015, 27, 7365-7371. [CrossRef]

66. Mi, Q.; Wang, Q.; Zang, S.; Mao, G.; Zhang, J.; Ren, X. RGO-coated elastic fibres as wearable strain sensors for full-scale detection of human motions. Smart Mater. Struct. 2017, 27, 015014. [CrossRef]

67. Montazerian, H.; Rashidi, A.; Dalili, A.; Najjaran, H.; Milani, A.; Hoorfar, M. Graphene-Coated Spandex Sensors Embedded into Silicone Sheath for Composites Health Monitoring and Wearable Applications. Small 2019, 15, e1804991. [CrossRef]

68. Niu, B.; Hua, T.; Hu, H.; Xu, B.; Tian, X.; Chan, K.; Chen, S. A highly durable textile-based sensor as a human-worn material interface for long-term multiple mechanical deformation sensing. J. Mater. Chem. C 2019, 7, 14651-14663. [CrossRef]

69. Hu, X.; Tian, M.; Xu, T.; Sun, X.; Sun, B.; Sun, C.; Liu, X.; Zhang, X.; Qu, L. Multiscale Disordered Porous Fibers for Self-Sensing and Self-Cooling Integrated Smart Sportswear. ACS Nano 2020, 14, 559-567. [CrossRef]

70. Tian, M.; Zhao, R.; Qu, L.; Chen, Z.; Chen, S.; Zhu, S.; Song, W.; Zhang, X.; Sun, Y.; Fu, R. Stretchable and Designable Textile Pattern Strain Sensors Based on Graphene Decorated Conductive Nylon Filaments. Macromol. Mater. Eng. 2019, $304,1900244$. [CrossRef]

71. Du, D.; Li, P.; Ouyang, J. Graphene coated nonwoven fabrics as wearable sensors. J. Mater. Chem. C 2016, 4, 3224-3230. [CrossRef]

72. Tang, Z.; Yao, D.; Du, D.; Ouyang, J. Highly machine-washable e-textiles with high strain sensitivity and high thermal conduction. J. Mater. Chem. C 2020, 8, 2741-2748. [CrossRef]

73. Simard-Normandin, M.; Ho, Q.B.; Rahman, R.; Ferguson, S.; Manga, K. Resistivity-strain analysis of graphene-based ink coated fabrics for wearable electronics. In Proceedings of the 2018 Pan Pacific Microelectronics Symposium, Big Island, HI, USA, 5 February 2018; pp. 1-9.

74. Zahid, M.; Papadopoulou, E.L.; Athanassiou, A.; Bayer, I.S. Strain-responsive mercerized conductive cotton fabrics based on PEDOT:PSS/graphene. Mater. Des. 2017, 135, 213-222. [CrossRef]

75. Rinaldi, A.; Tamburrano, A.; Sarto, M.S. Graphene nanoplatelets-based smart textile for kinesthetic monitoring. In Proceedings of the 16th IEEE SENSORS Conference, Glasgow, UK, 30 October 2017; pp. 1-3.

76. Liu, X.; Liu, D.; Lee, J.H.; Zheng, Q.; Du, X.; Zhang, X.; Xu, H.; Wang, Z.; Wu, Y.; Shen, X.; et al. Spider-Web-Inspired Stretchable Graphene Woven Fabric for Highly Sensitive, Transparent, Wearable Strain Sensors. ACS Appl. Mater. Interfaces 2019, 11, 2282-2294. [CrossRef]

77. Liu, X.; Tang, C.; Du, X.; Xiong, S.; Xi, S.; Liu, Y.; Shen, X.; Zheng, Q.; Wang, Z.; Wu, Y.; et al. A highly sensitive graphene woven fabric strain sensor for wearable wireless musical instruments. Mater. Horizons 2017, 4, 477-486. [CrossRef]

78. Liu, W.; Huang, Y.; Peng, Y.; Walczak, M.S.; Wang, D.; Chen, Q.; Liu, Z.; Li, L. Stable Wearable Strain Sensors on Textiles by Direct Laser Writing of Graphene. ACS Appl. Nano Mater. 2020, 3, 283-293. [CrossRef]

79. Wang, S.; Ning, H.; Hu, N.; Liu, Y.; Liu, F.; Zou, R.; Huang, K.; Wu, X.; Weng, S. Alamusi Environmentally-Friendly and Multifunctional Graphene-Silk Fabric Strain Sensor for Human-Motion Detection. Adv. Mater. Interfaces 2019, 7, 1901507. [CrossRef]

80. Ren, J.; Wang, C.; Zhang, X.; Carey, T.; Chen, K.; Yin, Y.; Torrisi, F. Environmentally-friendly conductive cotton fabric as flexible strain sensor based on hot press reduced graphene oxide. Carbon 2017, 111, 622-630. [CrossRef]

81. He, S.; Xin, B.; Chen, Z.; Liu, Y. Flexible and highly conductive Ag/G-coated cotton fabric based on graphene dipping and silver magnetron sputtering. Cellulose 2018, 25, 3691-3701. [CrossRef]

82. Zheng, Y.; Li, Y.; Zhou, Y.; Dai, K.; Zheng, G.; Zhang, B.; Liu, C.; Shen, C. High-Performance Wearable Strain Sensor Based on Graphene/Cotton Fabric with High Durability and Low Detection Limit. ACS Appl. Mater. Interfaces 2019, 12, $1474-1485$. [CrossRef]

83. Kim, S.J.; Song, W.; Yi, Y.; Min, B.K.; Mondal, S.; An, K.-S.; Choi, C.-G. High Durability and Waterproofing rGO/SWCNTFabric-Based Multifunctional Sensors for Human-Motion Detection. ACS Appl. Mater. Interfaces 2018, 10, 3921-3928. [CrossRef] [PubMed]

84. Xu, L.; Liu, Z.; Zhai, H.; Chen, X.; Sun, R.; Lyu, S.; Fan, Y.; Yi, Y.; Chen, Z.; Jin, L.; et al. Moisture-Resilient Graphene-Dyed Wool Fabric for Strain Sensing. ACS Appl. Mater. Interfaces 2020, 12, 13265-13274. [CrossRef] [PubMed]

85. Qu, J.; He, N.; Patil, S.V.; Wang, Y.; Banerjee, D.; Gao, W. Screen Printing of Graphene Oxide Patterns onto Viscose Nonwovens with Tunable Penetration Depth and Electrical Conductivity. ACS Appl. Mater. Interfaces 2019, 11, 14944-14951. [CrossRef] [PubMed]

86. Wang, D.; Li, D.; Zhao, M.; Xu, Y.; Wei, Q. Multifunctional wearable smart device based on conductive reduced graphene oxide/polyester fabric. Appl. Surf. Sci. 2018, 454, 218-226. [CrossRef]

87. Liubc, H.; Li, Q.; Bu, Y.; Zhang, N.; Wang, C.; Pan, C.; Mi, L.; Guo, Z.; Liu, C.; Shen, C. Stretchable conductive nonwoven fabrics with self-cleaning capability for tunable wearable strain sensor. Nano Energy 2019, 66, 104143. [CrossRef]

88. Yin, B.; Wen, Y.; Hong, T.; Xie, Z.; Yuan, G.; Ji, Q.; Jia, H. Highly Stretchable, Ultrasensitive, and Wearable Strain Sensors Based on Facilely Prepared Reduced Graphene Oxide Woven Fabrics in an Ethanol Flame. ACS Appl. Mater. Interfaces 2017, 9, 32054-32064. [CrossRef]

89. Karim, N.; Afroj, S.; Tan, S.; He, P.; Fernando, A.; Carr, C.; Novoselov, K. Scalable Production of Graphene-Based Wearable E-Textiles. ACS Nano 2017, 11, 12266-12275. [CrossRef]

90. Moriche, R.; Jiménez-Suárez, A.; Sánchez, M.; Prolongo, S.; Ureña, A. Graphene nanoplatelets coated glass fibre fabrics as strain sensors. Compos. Sci. Technol. 2017, 146, 59-64. [CrossRef] 
91. Chun, S.; Son, W.; Kim, D.W.; Lee, J.; Min, H.; Jung, H.; Kwon, D.; Kim, A.-H.; Kim, Y.-J.; Lim, S.K.; et al. Water-Resistant and Skin-Adhesive Wearable Electronics Using Graphene Fabric Sensor with Octopus-Inspired Microsuckers. ACS Appl. Mater. Interfaces 2019, 11, 16951-16957. [CrossRef]

92. Samad, Y.A.; Komatsu, K.; Yamashita, D.; Li, Y.; Zheng, L.; Alhassan, S.M.; Nakano, Y.; Liao, K. From sewing thread to sensor: Nylon®fiber strain and pressure sensors. Sens. Actuators B Chem. 2017, 240, 1083-1090. [CrossRef]

93. Souri, H.; Bhattacharyya, D. Highly Stretchable Multifunctional Wearable Devices Based on Conductive Cotton and Wool Fabrics. ACS Appl. Mater. Interfaces 2018, 10, 20845-20853. [CrossRef] [PubMed]

94. Lee, H.; Glasper, M.J.; Li, X.; Nychka, J.A.; Batcheller, J.; Chung, H.; Chen, Y. Preparation of fabric strain sensor based on graphene for human motion monitoring. J. Mater. Sci. 2018, 53, 9026-9033. [CrossRef]

95. Yang, Z.; Pang, Y.; Han, X.L.; Yang, Y.; Ling, J.; Jian, M.; Zhang, Y.; Yang, Y.; Ren, T.L. Graphene Textile Strain Sensor with Negative Resistance Variation for Human Motion Detection. ACS Nano 2018, 12, 9134-9141. [CrossRef] [PubMed]

96. Reddy, K.R.; Gandla, S.; Gupta, D. Highly Sensitive, Rugged, and Wearable Fabric Strain Sensor Based on Graphene Clad Polyester Knitted Elastic Band for Human Motion Monitoring. Adv. Mater. Interfaces 2019, 6, 1900409. [CrossRef]

97. Cai, G.; Yang, M.; Xu, Z.; Liu, J.; Tang, B.; Wang, X. Flexible and wearable strain sensing fabrics. Chem. Eng. J. 2017, 325, 396-403. [CrossRef]

98. Seyedin, S.; Zhang, P.; Naebe, M.; Qin, S.; Chen, J.; Wang, X.; Razal, J. Textile strain sensors: A review of the fabrication technologies, performance evaluation and applications. Mater. Horizons 2019, 6, 219-249. [CrossRef]

99. Meng, Q.; Liu, Z.; Cai, R.; Han, S.; Lu, S.; Liu, T. Non-oxidized graphene/elastomer composite films for wearable strain and pressure sensors with ultra-high flexibility and sensitivity. Polym. Adv. Technol. 2020, 31, 214-225. [CrossRef]

100. Wang, C.; Xia, K.; Wang, H.; Liang, X.; Yin, Z.; Zhang, Y. Advanced Carbon for Flexible and Wearable Electronics. Adv. Mater. 2019, 31, e1801072. [CrossRef]

101. Yan, T.; Wang, Z.; Pan, Z. Flexible strain sensors fabricated using carbon-based nanomaterials: A review. Curr. Opin. Solid State Mater. Sci. 2018, 22, 213-228. [CrossRef]

102. Han, S.O.; Ahn, H.J.; Cho, D. Hygrothermal effect on henequen or silk fiber reinforced poly(butylene succinate) biocomposites. Compos. Part B Eng. 2010, 41, 491-497. [CrossRef]

103. Li, B.; Dong, Y.; Li, L. Preparation and catalytic performance of Fe(III)-citric acid-modified cotton fiber complex as a novel cellulose fiber-supported heterogeneous photo-Fenton catalyst. Cellulose 2015, 22, 1295-1309. [CrossRef]

104. Liu, Z. Experimental Research on the Engineering Characteristics of Polyester Fiber-Reinforced Cement-Stabilized Macadam. J. Mater. Civ. Eng. 2015, 27, 04015004. [CrossRef]

105. Zhang, H.; Wu, W.; Cao, J.; Tong, M.; Xu, H.; Mao, Z.; Ma, H. Magnetic induced wet-spinning of graphene oxide sheets grafted with ferroferric oxide and the ultra-strain and elasticity of sensing fiber. Compos. Part B Eng. 2019, 170, 1-10. [CrossRef]

106. Yang, Z.; Niu, Y.; Zhao, W.; Zhang, Y.; Zhang, H.; Zhang, C.; Zhang, W.; Xiang, X.; Li, Q. Nanoparticle intercalation-modulated stretchable conductive graphene fibers with combined photoelectric properties. Carbon 2019, 141, 218-225. [CrossRef]

107. Li, X.; Cai, W.; Colombo, L.; Ruoff, R.S. Evolution of Graphene Growth on Ni and Cu by Carbon Isotope Labeling. Nano Lett. 2009, 9, 4268-4272. [CrossRef]

108. Meng, C.; Jiang, W.; Huang, Z.; Liu, T.; Feng, J. Fabrication of a Highly Conductive Silk Knitted Composite Scaffold by Two-Step Electrostatic Self-Assembly for Potential Peripheral Nerve Regeneration. ACS Appl. Mater. Interfaces 2020, 12, 12317-12327. [CrossRef]

109. Li, H.; Du, Z. Preparation of a Highly Sensitive and Stretchable Strain Sensor of MXene/Silver Nanocomposite-Based Yarn and Wearable Applications. ACS Appl. Mater. Interfaces 2019, 11, 45930-45938. [CrossRef]

110. Zhangabc, M.; Wangab, M.; Zhangab, M.; Gaoae, Q.; Fengabc, X.; Zhangd, Y.; Hu, J.-T.; Wu, G. Stretchable conductive $\mathrm{Ni@Fe3O4@Polyester} \mathrm{fabric} \mathrm{strain} \mathrm{sensor} \mathrm{with} \mathrm{negative} \mathrm{resistance} \mathrm{variation} \mathrm{and} \mathrm{electromagnetic} \mathrm{interference} \mathrm{shielding.}$ Org. Electron. 2020, 81, 105677. [CrossRef]

111. Wang, F.; Jiang, J.; Sun, F.; Sun, L.; Wang, T.; Liu, Y.; Li, M. Flexible wearable graphene/alginate composite non-woven fabric temperature sensor with high sensitivity and anti-interference. Cellulose 2020, 27, 2369-2380. [CrossRef]

112. Li, S.; Chen, T.; Xiao, X. Periodically inlaid carbon fiber bundles in the surface of honeycomb woven fabric for fabrication of normal pressure sensor. J. Mater. Sci. 2020, 55, 6551-6565. [CrossRef]

113. Kim, J.K.; Sham, M.L. Impact and delamination failure of woven-fabric composites. Compos. Sci. Technol. 2000, 60, 745-761. [CrossRef]

114. Tohidi, S.D.; Zille, A.; Catarino, A.W.; Rocha, A.M. Effects of Base Fabric Parameters on the Electro-Mechanical Behavior of Piezoresistive Knitted Sensors. IEEE Sensors J. 2018, 18, 4529-4535. [CrossRef]

115. Li, Y.; Miao, X.; Niu, L.; Jiang, G.; Ma, P. Human Motion Recognition of Knitted Flexible Sensor in Walking Cycle. Sensors 2019, 20, 35. [CrossRef] [PubMed]

116. Lee, S.; Kim, M.O.; Kang, T.; Park, J.; Choi, Y. Knit Band Sensor for Myoelectric Control of Surface EMG-Based Prosthetic Hand. IEEE Sensors J. 2018, 18, 8578-8586. [CrossRef]

117. Wang, S.; Wang, D.; Chung, D.D.L.; Chung, J.H. Method of sensing impact damage in carbon fiber polymer-matrix composite by electrical resistance measurement. J. Mater. Sci. 2006, 41, 2281-2289. [CrossRef] 